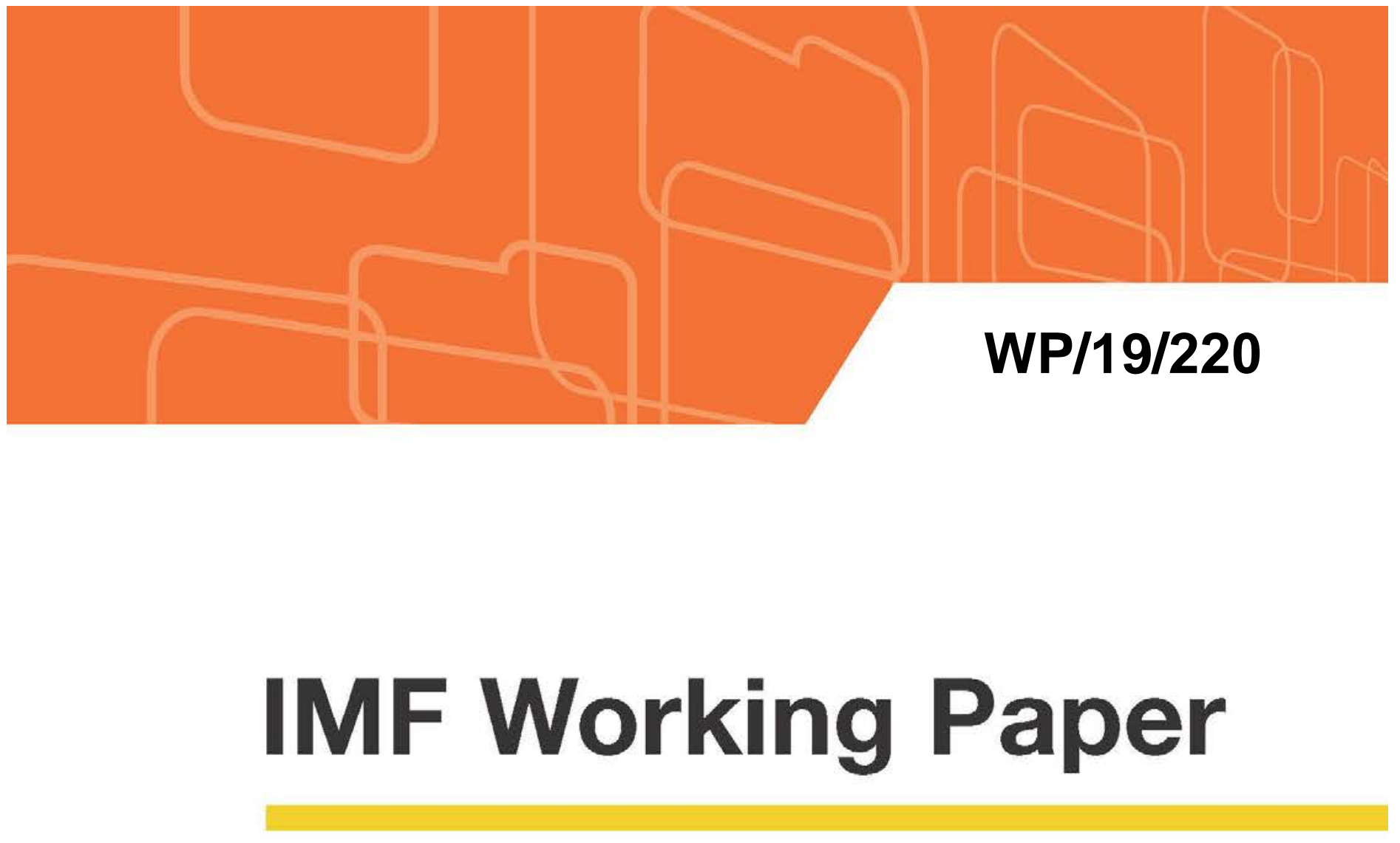

\title{
Interconnectedness and Contagion Analysis: A Practical Framework
}

by Jana Bricco and TengTeng Xu

IMF Working Papers describe research in progress by the author(s) and are published to elicit comments and to encourage debate. The views expressed in IMF Working Papers are those of the author(s) and do not necessarily represent the views of the IMF, its Executive Board, or IMF management.

$$
\text { I N T E R N A T I O N A L M O N E T A R Y F U N D }
$$




\title{
IMF Working Paper
}

Monetary and Capital Markets Department (MCM)

Interconnectedness and Contagion Analysis: A Practical Framework

Prepared by Jana Bricco and TengTeng $X \mathbf{u}^{1}$

Authorized for distribution by Martin Čihák

October 2019

\section{IMF Working Papers describe research in progress by the author(s) and are published to elicit comments and to encourage debate. The views expressed in IMF Working Papers are those of the author(s) and do not necessarily represent the views of the IMF, its Executive Board, or IMF management.}

\begin{abstract}
The analysis of interconnectedness and contagion is an important part of the financial stability and risk assessment of a country's financial system. This paper offers detailed and practical guidance on how to conduct a comprehensive analysis of interconnectedness and contagion for a country's financial system under various circumstances. We survey current approaches at the IMF for analyzing interconnectedness within the interbank, cross-sector and cross-border dimensions through an overview and examples of the data and methodologies used in the Financial Sector Assessment Program. Finally, this paper offers practical advice on how to interpret results and discusses potential financial stability policy recommendations that can be drawn from this type of in-depth analysis.
\end{abstract}

JEL Classification Numbers: G0, G1, G2, and C5.

Keywords: Interconnectedess; Contagion; Financial Stability; Financial Systems; Risk Analysis, Systemic Risk.

Author’s E-Mail Addresses: JBricco@imf.org; TXu@imf.org

\footnotetext{
${ }^{1}$ We are grateful to Adrian Alter, Carlos Caceres, Martin Čihák, Ziya Gorpe, Tumer Kapan, Izabela Karpowicz, Graeme Littler, Sheheryar Malik, Erlend Nier, Thorvardur Olafsson, Hiroko Oura, Jorge Salas, Juan Sole, Giovanni Ugazio, and country authorities of the referenced Financial Sector Assessment Program for their comments and feedback.
} 


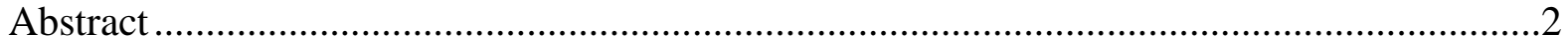

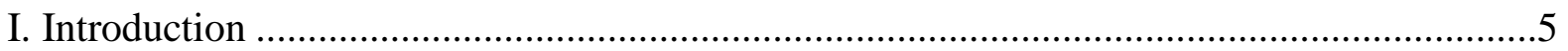

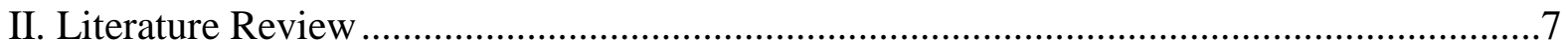

III. Mapping of the Financial System (Phase I) ……….........................................................

A. Mapping of Interbank Exposures............................................................................10

B. Mapping of Cross-Sectoral Exposures ......................................................................12

C. Mapping of Cross-Border Exposures ........................................................................15

IV. Interbank, Cross-Sector, and Cross-Border Contagion Analysis (Phase II).......................17

A. How to Analyze Interbank Interconnectedness and Contagion? ..............................19

B. How to Analyze Cross-Sectoral Interconnectedness and Contagion? ......................27

C. How to Analyze Cross-Border Interconnectedness and Contagion? .........................34

V. Practical Advice for the Presentation of Results and Policy Recommendations (Phase III)

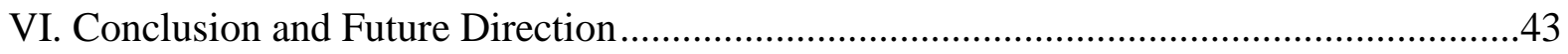

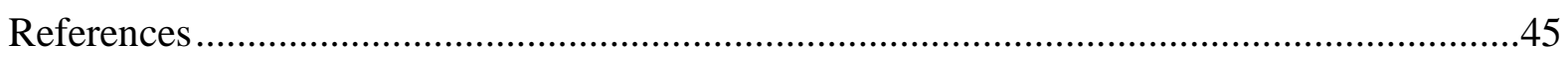

Tables

1. Characteristics of Different Analytical Approaches on Interconnectedness and Contagion Analysis..................................................................................................................

2. Past FSAP Recommendations Based on Interconnectedness and Contagion Analysis........42

Figures

1. Comprehensive Interconnectedness and Contagion Analysis ...............................................6

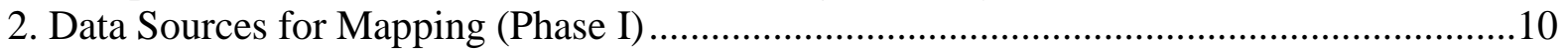

3. Interbank Mapping—Example: Spain ................................................................................11

4. Domestic Interbank Network Graph Using Gephi-Example: Luxembourg.......................12

5. Cross-Sector Mapping_Example: Romania.....................................................................13

6. Cross-Sector Mapping —Example: Poland ...........................................................................14

7. Network Graph for the Main FMIs in China and their Clearing Members ..........................14

8. Types of Claims in BIS Consolidated Banking Statistics.....................................................15

9. Cross-Border Mapping—Example: Spain ............................................................................16

10. Cross-Border Mapping_Example: Spain ........................................................................17

11. Approach to Interconnectedness and Contagion Analysis (Phase II) ................................18

12. Examples of Approaches in the FSAP ........................................................................18

13. Iteration process in Espinosa-Vega and Sole...................................................................2

14. Interbank Contagion Analysis using EVS Method-Example: Luxembourg.....................21

15. Bank Distress Sensitivity to Model Assumptions-Example: Euro Area..........................22

16. Example of Variance Decomposition and Indicators Using Diebold and Yilmaz .............24

17. SyRIN indicator using PoDs-Example: Luxembourg ......................................................25 
18. Capital Adequacy Ratio under Adverse Scenario—Example: Indonesia...........................27

19. Banks and Insurers Interconnections_Example: Luxembourg ........................................2

20. Domestic Linkages_Example: Finland.......................................................................28

21. Derivation of Probability of Distress for Investment Funds—Example: Luxembourg......30

22. Systemic Risk in the Bank and Insurance Sector—Example: United Kingdom .................30

23. Large-value Payment System Network Analysis_Example: Jamaica ...............................31

24. Bank-Sovereign Nexus. Potential Channels of Contagion .................................................32

25: Intersectoral Exposures_Example: Romania ....................................................................33

26: Market-Implied Contingent Liabilities of the Financial Sector—Example: United States

27. Cross-Border Contagion for Spain (EVS) (Example: Spain FSAP)...................................35

28. Interconnectedness among Banking Indices (Example: Spain FSAP) ................................37

29. Contribution to Systemic Risk (Example: New Zealand FSAP) ..........................................38

30. Cross-Border Spillover of Spain Credit Shock (Example: Spain FSAP) .............................39

31. Policy Discussion and Integration of Results (Phase III) .....................................................40

32. Mapping Tools to Objectives: Structural Dimension ..........................................................41 


\section{INTRODUCTION}

The Global Financial Crisis of 2007-2009, international transmission of financial shocks after the failure of Lehman Brothers, and the distress of AIG underscored the importance of a better understanding of contagion channels among financial institutions. In the past 10 years, the analysis of interconnectedness and contagion has become essential to the IMF's financial stability and risk assessment work, not only in the context of Financial Sector Assessment Program (FSAP), but also in macro-financial surveillance, Spillover Reports, and the Global Financial Stability Report (GFSR). ${ }^{2}$

In this paper, we distinguish between the concepts of "interconnectedness" and "contagion." As in Forbes (2012), "interconnectedness" or "interdependency” is defined as financial linkages or correlations across the market prices of financial institutions during all states of the world. Following Forbes and Rigobon (2002), "contagion” is defined as "a significant increase in cross-market linkages after a shock to one country (or group of countries)” or more generally, linkages after a shock to one or more financial institutions. ${ }^{3}$

Although interconnectedness and contagion can manifest in different ways (e.g., "normal” or "crisis" states), they can arise from both direct and indirect linkages among financial institutions. Direct linkages among financial institutions could be attributed to direct balance sheet exposures, such as interbank exposures (Allen and Gale 2000; Freixas, Parigi, and Rochet 2000). Banks and non-bank financial institutions could be directly connected through multiple channels, including deposits and loans. Indirect linkages could be due to exposures to common assets (Cont and Schaanning 2017, 2019) including mark-to-market losses due to fire sales (Shleifer and Vishny 1992; Cifuentes, Shin, and Ferrucci 2005), information spillover (Aghion, Bolton, and Dewatripont 2000; and Acharya and Thakor 2016), or market and investor perceptions (for example, perceived common business models). As noted in Diebold and Yilmaz (2014), interconnectedness and contagion of financial institutions are also closely linked with modern measures of systemic risks. ${ }^{4}$

This paper takes stock of the current approaches for analyzing interconnectedness and contagion at the IMF and offers practical guidance on how to conduct a comprehensive

\footnotetext{
2 The prominence of interconnectedness and contagion analysis in IMF FSAP is partly driven by the 2014 FSAP Board Review, which mandated continued focus on all components of financial stability assessment towards systemic risk. It called for (i) a deeper analytical treatment of interconnectedness and better integration with stress tests, and (ii) more systematic analysis of cross-border exposure and spillovers, based on data availability. See www.imf.org/external/np/pp/eng/2014/081814.pdf.

${ }^{3}$ For a survey on the literature on cross-border contagion and crisis, see Forbes (2012).

${ }^{4}$ This paper defines systemic risk as "a risk of disruption to financial services that is (i) caused by an impairment of all or parts of the financial system and (ii) has the potential to have serious negative consequences for the real economy" (IMF, BIS, and FSB 2009). For a review of the theoretical literature on contagion in financial networks, see Allen and Babus (2009) and Glasserman and Young (2016). For general surveys on contagion and systemic risks, see Benoit and others (2017) and Bisias and others (2012).
} 
analysis for a country's financial system under various circumstances. Specifically, this paper discusses the data and methodologies that can be used for interconnectedness analysis and provides an overview of the policy recommendations that can be drawn from an in-depth analysis. In doing so, the paper provides examples of interconnectedness and contagion analysis conducted in recent FSAP and offers practical advice on the interpretation of results and discusses potential policy recommendations.

A comprehensive interconnectedness and contagion analysis of a country's financial system would involve three main phases (Figure 1). The first phase is the mapping of the financial system. Building upon insights gained from the mapping phase, the second phase analyzes or models interbank, cross-sectoral, and cross-border linkages. In other words, the analysis should go beyond pure interbank exposures and aim to cover cross-sectoral linkages-for instance, between banks and insurance companies, investment funds, non-financial businesses and corporates, households, and/or the sovereign. Cross-border channels between domestic and foreign financial sectors also form an important part of a comprehensive interconnectedness analysis, especially for financial hubs and countries with a large presence of foreign financial entities or sizable external liabilities. The third phase involves policy discussions, which help to form a view of systemic risks in the financial system. Given that the interconnectedness among financial institutions could arise from both direct and indirect linkages, it is important to rely on both balance sheet and market data. If possible, the analysis should use granular balance sheet data, in addition to aggregate-level information, to shed light on the cross-sectoral variations and risk transmissions among individual financial institutions. Due to these connections and data sources, it is often helpful to apply several models to arrive at a holistic view of contagion channels in the financial system.

\section{Figure 1. Comprehensive Interconnectedness and Contagion Analysis}

\section{Phase I: Mapping of the Financial System}

Phase II: Analysis or modeling of interbank, cross-sectoral and cross-border linkages
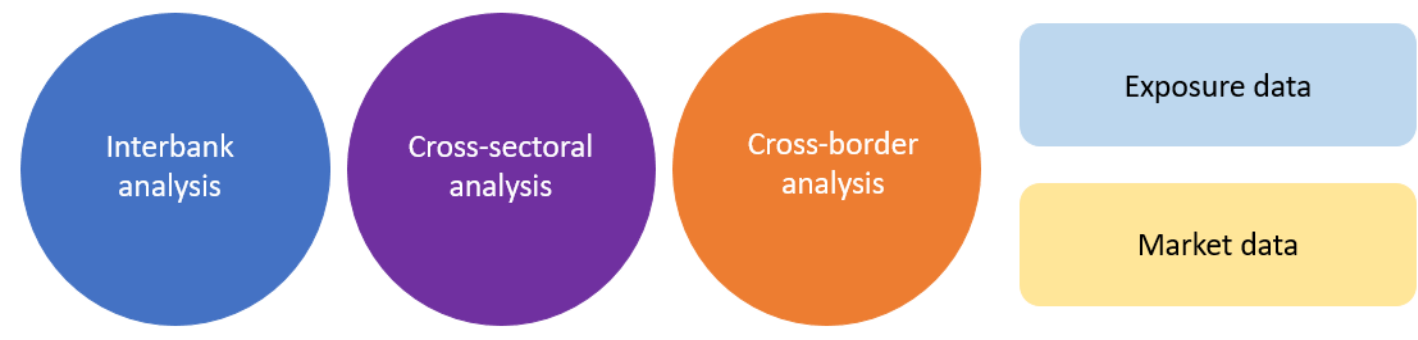

Phase III: Policy discussions - form view on Systemic Risks in the financial system

The results of interconnectedness and contagion analysis should be viewed in conjunction with different work streams of financial stability analysis and oversight. For example, 
contagion analysis could be closely related to banking sector stress tests through the integration of solvency and liquidity stress testing and interbank second round effects. Policy makers should use both stress testing and contagion analysis to form a view of systemic risks in the financial system. In addition, contagion analysis could help identify strong crossborder linkages that should be followed up in supervisory and resolution assessments. Furthermore, the systemic risk conclusion from a comprehensive interconnectedness and contagion analysis could serve as inputs to macro-prudential analysis and systemic risk oversight.

The contribution of the paper is two-fold. First, it is one of the first survey papers on how to conduct a comprehensive interconnectedness and contagion analysis. In contrast to some of the previous survey papers in analyzing systemic risks (e.g., Benoit and others, 2017; Bisias and others, 2012; Blancher and others, 2013), the focus of this paper is on interconnectedness and contagion analysis, an increasingly important component of financial stability and risk assessment work. ${ }^{5}$ Second, this paper discusses the policy implications from interconnectedness and contagion analysis, while past surveys on systemic risks have largely focused on the methodologies rather than policy discussions.

The rest of the paper is structured as follows. Section II offers a brief literature review on recent developments in analyzing interconnectedness and contagion among financial institutions empirically. Section III discusses how to approach the mapping of domestic and external exposures of a financial system (Phase I). Section IV provides an overview of various methodologies that can be used to uncover interdependence and contagion in financial entities from the interbank, cross-sector, and cross-border dimensions (Phase II). Section V offers some practical advice on the presentation of results and discusses policy recommendations that can be derived from interconnectedness and contagion analysis (Phase III). Section VI offers some concluding remarks, including avenues for future research.

\section{LITERATURE REVIEW}

This literature review surveys the latest empirical developments in analyzing the interconnectedness and contagion of financial institutions. The interconnectedness between financial institutions could arise from both direct and indirect linkages, such as common exposures and investors' perceptions. We group the approaches into two categories: first, network type of approaches that capture direct connectedness between financial institutions based on exposure data; second, market-based approaches that capture indirect connectedness largely based on market and financial asset price data, and in certain cases a combination of market and exposure data.

\footnotetext{
${ }^{5}$ While the boundary between interconnectedness, contagion, and systemic risk can be blurred in market data analysis, this paper shows that some of the methodologies used in systemic risk analysis also fit in the broader interconnectedness analysis of a country's financial system.
} 
The existing literature on the effect of network connections on financial stability points to mixed evidence. By diversifying the risk across individual market participants, network exposures can be stabilizing through risk sharing, but they can also have negative effects by creating additional channels through which shocks can spread more quickly. The tension between these two forces has been explored in a variety of papers, including Allen and Gale (2000), Freixas, Parigi, and Rochet (2000), and Gai, Haldane and Kapadia (2011).

Analyses of network connections of financial institutions have been based on both supervisory and publicly available data. In country-specific studies, Boss and others (2004), Inaoka and others (2004), Alter, Craig, and Raupach (2015), Cingano, Manaresi, and Sette (2016), and Iyer and Peydro (2011) analyze financial contagion in interbank markets using confidential supervisory data. Upper (2011) surveys the findings of counterfactual simulations used to estimate the danger of contagion resulting from exposures in the interbank loan market. Paddrik, Rajan, and Young (2016) analyze counterparty exposures in the credit default swaps market and examine the impact of severe credit shocks on the demand for variation margin (the payments counterparties make to offset price changes). On indirect exposures, Cont and Schaanning $(2017,2019)$ quantify interconnectedness through common asset holdings, using the exposures of European banks.

In global banking network analysis, Minoiu and Reyes (2013) and Minoiu and others (2015) analyze cross-border bank contagion using publicly available country-level banking statistics from the Bank for International Settlements (BIS), with the latter analyzing the ability of connectedness to predict systemic banking crisis. Aldasoro and Ehlers (2019) use BIS banking statistics to analyze the concentration in cross-border banking and find that concentration is mainly due to links involving advanced economies. Hale (2012), Hale, Kapan, Minoiu (2016), and Cai and others (2018) use interbank syndicated loans to construct a global bank network.

Several assessments under the IMF FSAP apply the Espinosa-Vega and Sole (2010) approach to examine cross-border bank exposures by considering the impact of both credit and funding shocks. More recently, Covi, Gorpe, and Kok (2019) use granular supervisory data to model the network of euro area banks' large exposures within the global banking system. They find that tipping points shifting the financial system from a less vulnerable state to a highly vulnerable state are a non-linear function of the combination of network structures and bank-specific characteristics. Finally, the Global VAR approach by Dees and others (2007) has been used to analyze the international spillover of financial shocks across countries, with Xu (2012), Beirne and Bricco (2014), and Eichmeier and Ng (2015) analyzing the international transmission of credit shocks.

Given that the access to confidential exposure data (supervisory information) is often limited, another strand of the literature relies on financial market data to analyze interconnectedness between financial institutions. This literature is closely related to that on systemic risk. Diebold and Yilmaz (2014) use equity returns or volatility data to examine the interlinkages 
between publicly traded financial entities, based on the Generalized Variance Decompositions of the underlying Vector Autoregression (VAR) model. Malik and Xu (2017) examine the global and bank-specific drivers of the interconnectedness measures derived using the Diebold and Yilmaz (2014) methodology and find that economic policy uncertainty and bank balance sheet variables such as profitability and the non-interest income share play an important role.

The Conditional Value-at-Risk (CoVaR) indicator by Adrian and Brunnermeier (2008) estimates the value at risk of the financial system conditional on institutions being under distress using market (equity data) and balance sheet information. The SRISK indicator by Acharya, Engle, and Richardson (2012) captures the expected capital shortage of a firm using debt, equity, and Marginal Expected Shortfall (MES) information, where MES is the expected loss an equity investor in a financial firm would experience if the overall market declined substantially. Systemic contingent claims analysis by Jobst and Gray (2013) measures systemic solvency risk using market-implied expected losses of financial institutions and quantifies the individual contributions to systemic risk and contingent liabilities of the financial sector during times of stress.

The Systemic Risk and Interconnectedness (SyRIN) tool developed by Cortes and others (2018) quantifies the impact of risk amplification mechanisms resulting from interconnectedness structures across banks and other financial intermediaries (including insurance and funds with publicly available market data). Finally, the Systemic Risk Monitor tool developed by Hamilton, Hughes, and Malone (2015) combines network analysis with Moody's CreditEdge platform to compute systemic risk measure to analyze interconnectedness and potential for contagion among financial entities. Statistically significant Granger causal connections between pairs of entities using bivariate vector autoregression models were used.

Given the significant progress made in analyzing the interconnectedness and contagion of financial institutions in recent years, the rest of this paper will present practical guidance and examples of how to conduct a comprehensive interconnectedness and contagion analysis using some of the methodologies discussed above.

\section{Mapping Of The Financial System (Phase I)}

Before embarking on a meaningful interconnectedness and contagion analysis, it is important to first provide a mapping of the interlinkages in a country's financial system (Phase I). For the domestic financial system, it is useful to examine the flow of funds, ownership network, and cross-sectoral and interbank exposures. On cross-border linkages, it is important to understand the type, destination, and origin of international exposures that could be relevant for an in-depth risk analysis.

The data for the mapping exercise comes from both public and confidential supervisory data (collected by supervisors). On interbank linkages, the exposure data is typically collected by 
the authorities (banking supervisors). On cross-sector linkages, the flow of funds data is sometimes collected by national authorities at the sectoral aggregate level, containing information on cross-sectoral linkages among economic sectors and between banks and nonbank financial institutions. In addition, some authorities collect supervisory data at the entity level, which could provide more granular information on cross-sector linkages. On crossborder linkages, the BIS's Consolidated Banking Statistics (CBS) and the Locational Banking Statistics (LBS) provide aggregate publicly-available information on cross-border banking linkages for BIS reporting countries. The IMF's International Financial Statistics (IFS) and Financial Soundness Indicators (FSI) databases provide detailed balance sheet information —including on foreign assets and liabilities_covering the aggregated banking system for most member countries, as well as nonbank financial institutions in selected jurisdictions. Moreover, the IMF’s International Investment Position (IIP) database provides aggregate information on cross-border equity and debt portfolio investments, while its Coordinated Portfolio Investment Survey (CPIS) provides similar but more detailed data on bilateral country-level cross-border portfolio investments. In addition, national authorities typically collect supervisory information on cross-border exposure both on the aggregate and entity levels (see Figure 2).

\section{Figure 2. Data Sources for Mapping (Phase I)}

\section{Phase I: Mapping of the Financial System}
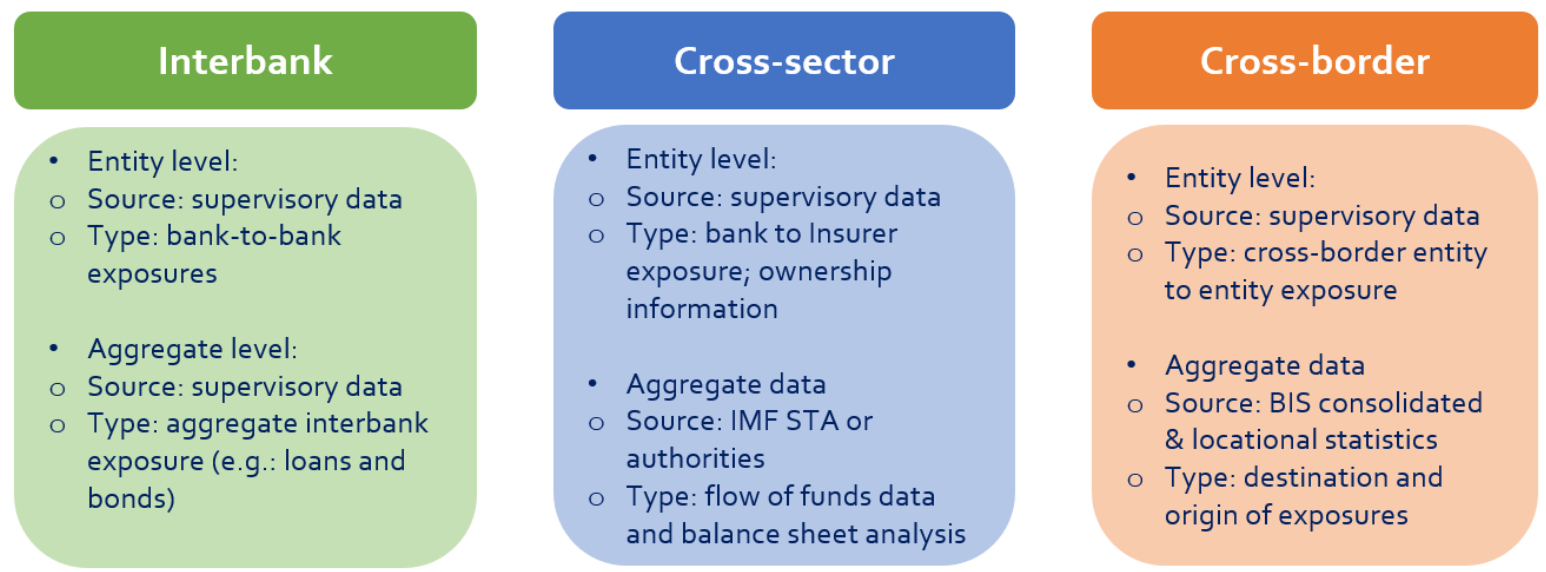

Note: Supervisory data is often confidential and not available in the public domain, with some exceptions (e.g. the U.S. Call Report).

\section{A. Mapping of Interbank Exposures}

On interbank exposures, it is useful to understand the type of exposures (e.g., loans, bonds, capital participation, and off-balance sheet exposures) and to compare the size of interbank and intra-group exposures in the financial system. In some countries, intra-group exposures are much more prominent than interbank exposures, which may suggest that interbank 
connectedness is not as important a source of contagion. If data is available, it is useful to understand the participants in the interbank market and the extent of concentration.

Example: 2017 Spain FSAP. This FSAP uses supervisory Bank of Spain data on interbank and intragroup exposures for interbank mapping. Figure 3 shows that compared with intragroup exposures, the interbank market is smaller in Spain, especially in loans, capital participation, and off-balance sheet exposures. Interbank exposures in Spain are highly concentrated in the five largest banks. Specifically, the top five Significant Institutions (SIs) account for more than 85 percent of loans and capital participation in the interbank market, and about half of the interbank bond exposures. Most of the interbank exposures are in the form of loans and bonds. This type of mapping exercise provides useful insights into the nature of interbank exposures in the Spanish banking system. These insights are helpful during Phase II-the network analysis on the domino effect of interbank contagion.

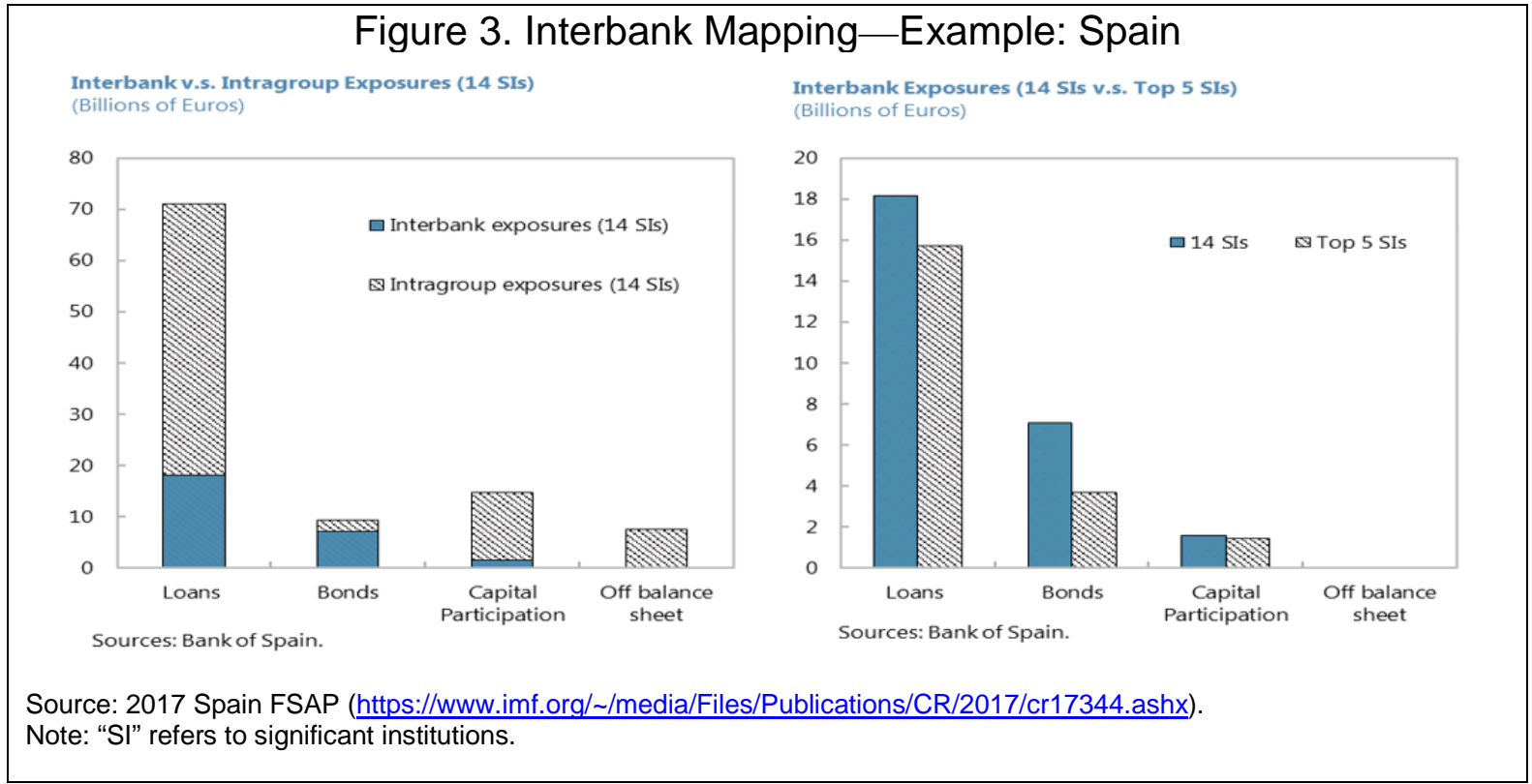

In mapping interconnectedness among financial institutions, it can be useful to visualize the underlying networks using software such as Gephi and NodeXL. ${ }^{6}$ Apart from visualization, these tools can be used to derive standard network metrics such as (i) centrality (e.g., outdegree: the number of links leaving a node/entity; in-degree: the number of links into a node; and closeness: the average length of the shortest paths from a node to all other nodes), (ii) distance (i.e., the average number of links separating the nodes in the network), and (iii) diameter (i.e., the maximum distance in the network). These network measures provide insights on the importance of individual financial institutions in a network setting.

\footnotetext{
${ }^{6}$ For further information on free open source software, please visit https://gephi.org for Gephi and https://www.smrfoundation.org for NodeXL.
} 
Example: 2017 Luxembourg FSAP. This FSAP uses Gephi to visualize the interbank network (see Figure 4). Visualizations were found to be a useful first step in presenting the connections in an intuitive manner ahead of an in-depth network analysis (Phase II). Figure 4 displays Luxembourg's domestic interbank network based on banks' total assets (as represented by the node size) and banks' exposures as a percent of common equity tier 1 capital (CET1), indicated by the blue lines. It illustrates a low level of domestic interconnectedness in the banking sector. Only a few banks stand out as having relatively stronger linkages to multiple other banks, while the rest of the network map appears sparsely connected. From this visualization, banks 1, 11, and 14 appear to have the largest exposures of the banks in the network sample. This network is further analysed in Phase II (see Figure 14).

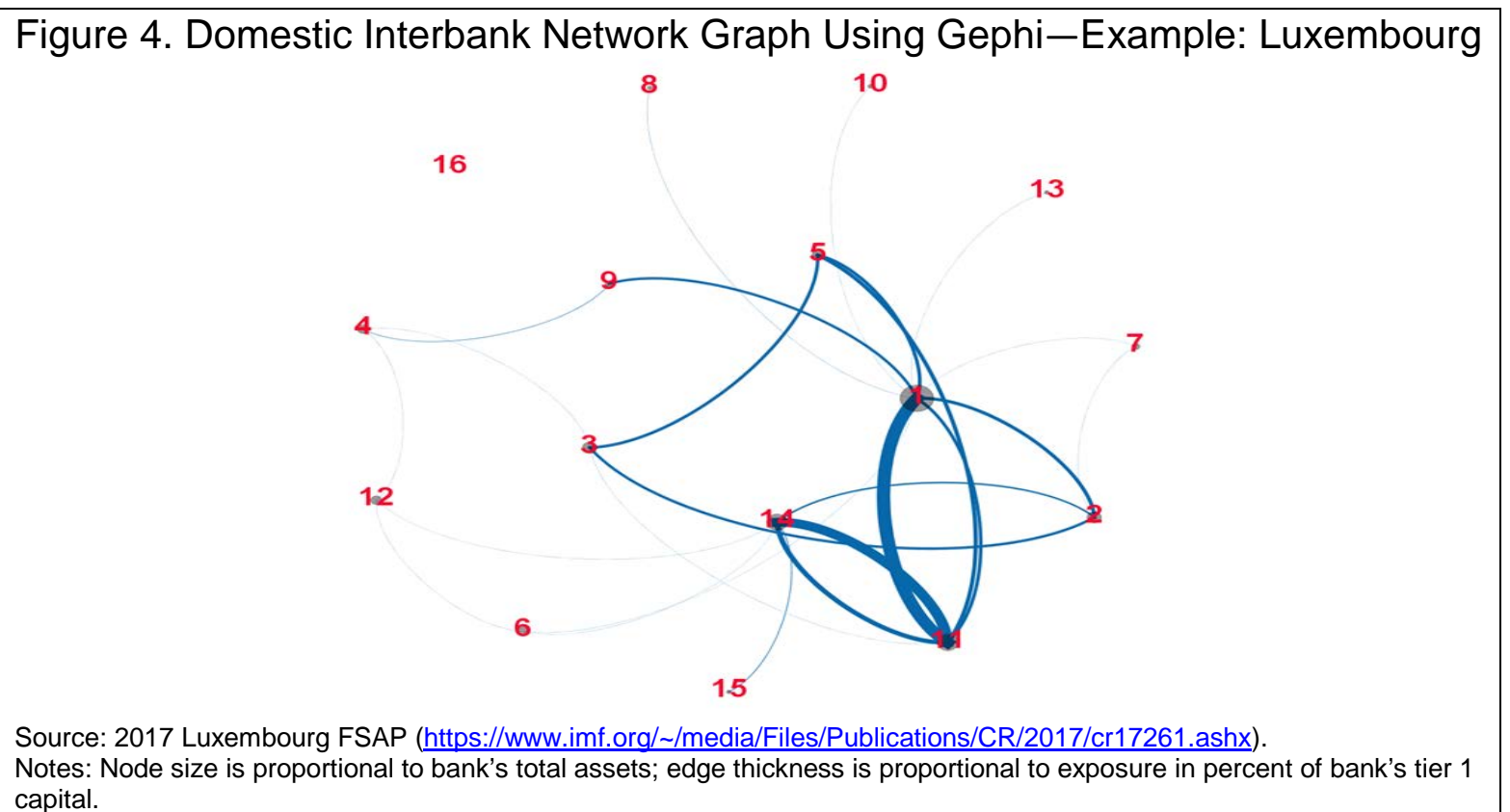

\section{B. Mapping of Cross-Sectoral Exposures}

For cross-sectoral analysis, the balance sheet analysis (BSA) developed by the IMF, which uses the aggregated sectoral balance sheets of an economy to estimate intersectoral exposures, is helpful for understanding how the financial sector is related to households, corporates, government, and the rest of the world from both asset and liability perspectives. In addition, the BSA can be used to map linkages within the financial system, for example, among banks, insurance companies, investment funds, pension funds, money market funds, etc. ${ }^{7}$ Depending on the granularity of the underlying data, the BSA can also analyze imbalances from the point of view of maturity and currency mismatches. For an overview of

\footnotetext{
${ }^{7}$ See IMF (2015a) for details on BSA in IMF surveillance.
} 
the linkages between the financial sector and the real economy, and across different segments of the financial sector, it would be useful to start the mapping exercise with BSA.

Example: 2018 Romania FSAP. The BSA in this FSAP examines the evolution of crosssectoral exposures from 2008 to 2016. In Figure 5, the red nodes represent net borrowers and the green nodes are net lenders. The arrows represent gross balance sheet exposures, and the nodes represent net exposures or imbalances. In Romania, corporates are the largest net borrowers as depicted by the large red node. Households and the rest of the world are the largest net lenders, shown by the sizable green nodes. Furthermore, the government sector changed from being a net lender in 2008 to a net borrower by 2016, in part due to repeated budget deficits. This type of mapping exercise based on balance sheet data can serve as a useful starting point to diagnose risks and to identify potential transmission channels of shocks for the financial sector.

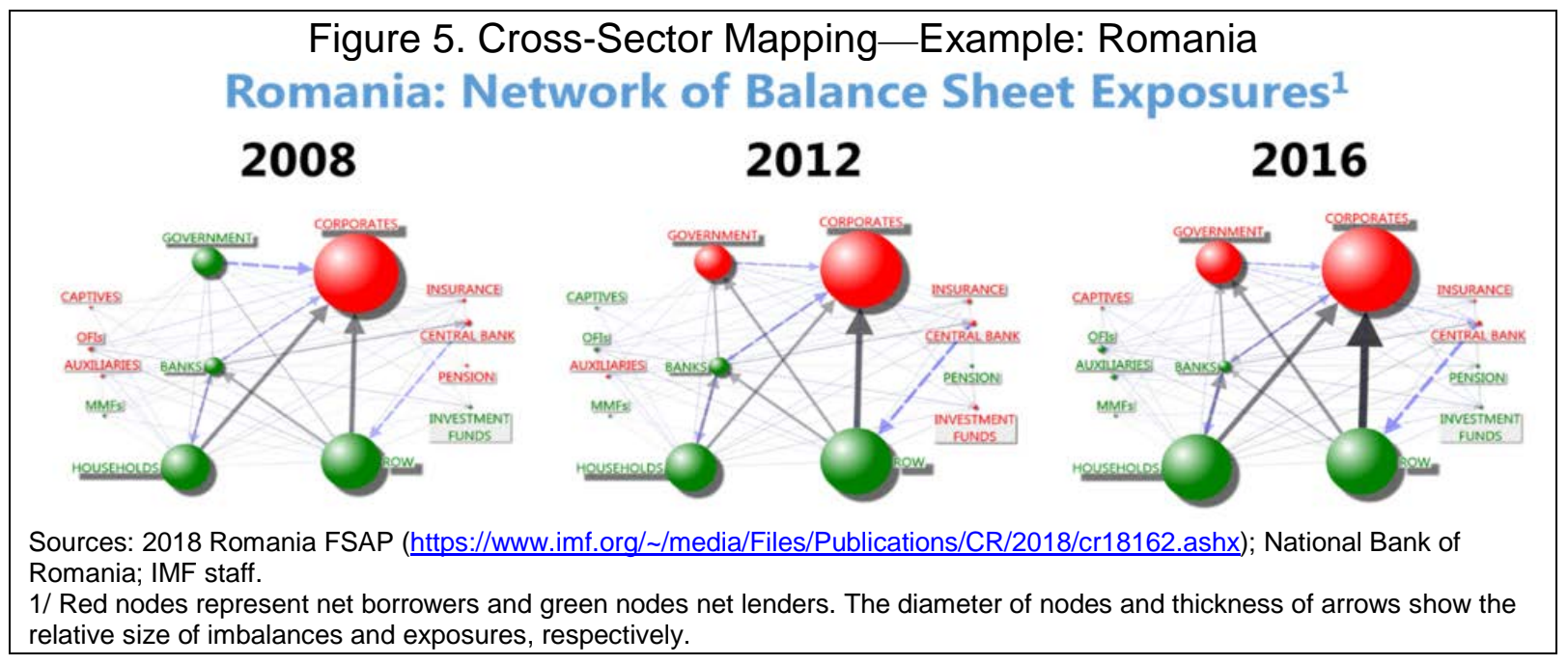

In addition to BSA, it is important to map the ownership structure within a country's financial system. The ownership information could shed light on the extent of state or foreign ownership of the domestic financial system. It could also provide information on the complexity of the conglomerate structure potentially present in the financial sector, which may involve sizable cross-holdings of financial sector assets.

Example: 2019 Poland FSAP. Using supervisory data, this FSAP maps the ownership network within Poland's financial system. Figure 6 shows that state and foreign entities have sizable ownership stakes in the domestic financial system, including banks and insurers. In terms of cross-sectoral exposures among financial institutions, insurance companies have sizable investments in the investment fund sector, while open-ended funds hold a large share of bank debt. The ownership network is informative as it offers some insights on the channels of risk transmission through ownership structures in the financial system. 


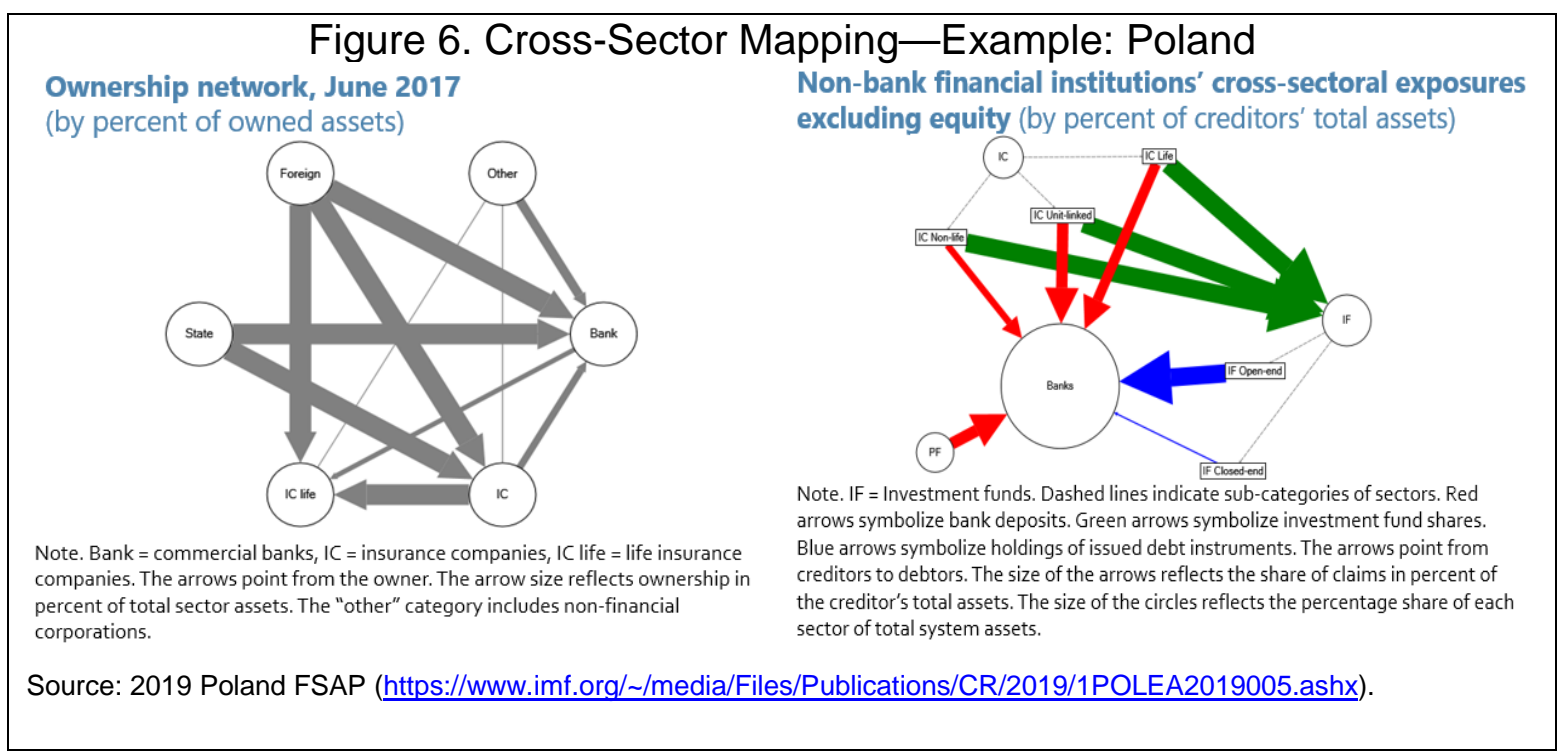

If data is available, it would be informative to map the linkages between financial institutions and Financial Markets Infrastructures (FMIs) to analyze the extent of concentration in a country's financial system. The degree of clustering in FMI membership could help shed light on the potential transmission of risks through central counterparties.

Example: 2017 China FSAP. Network graph analysis was used in the China FSAP to visualize the FMI network. This analysis showed that the membership of FMIs is highly clustered, with about 80 percent of members of the futures exchanges belonging to all the exchanges. In addition, the largest eight banks are connected to all eight FMIs, constituting a potential source of vulnerability (Figure 7).

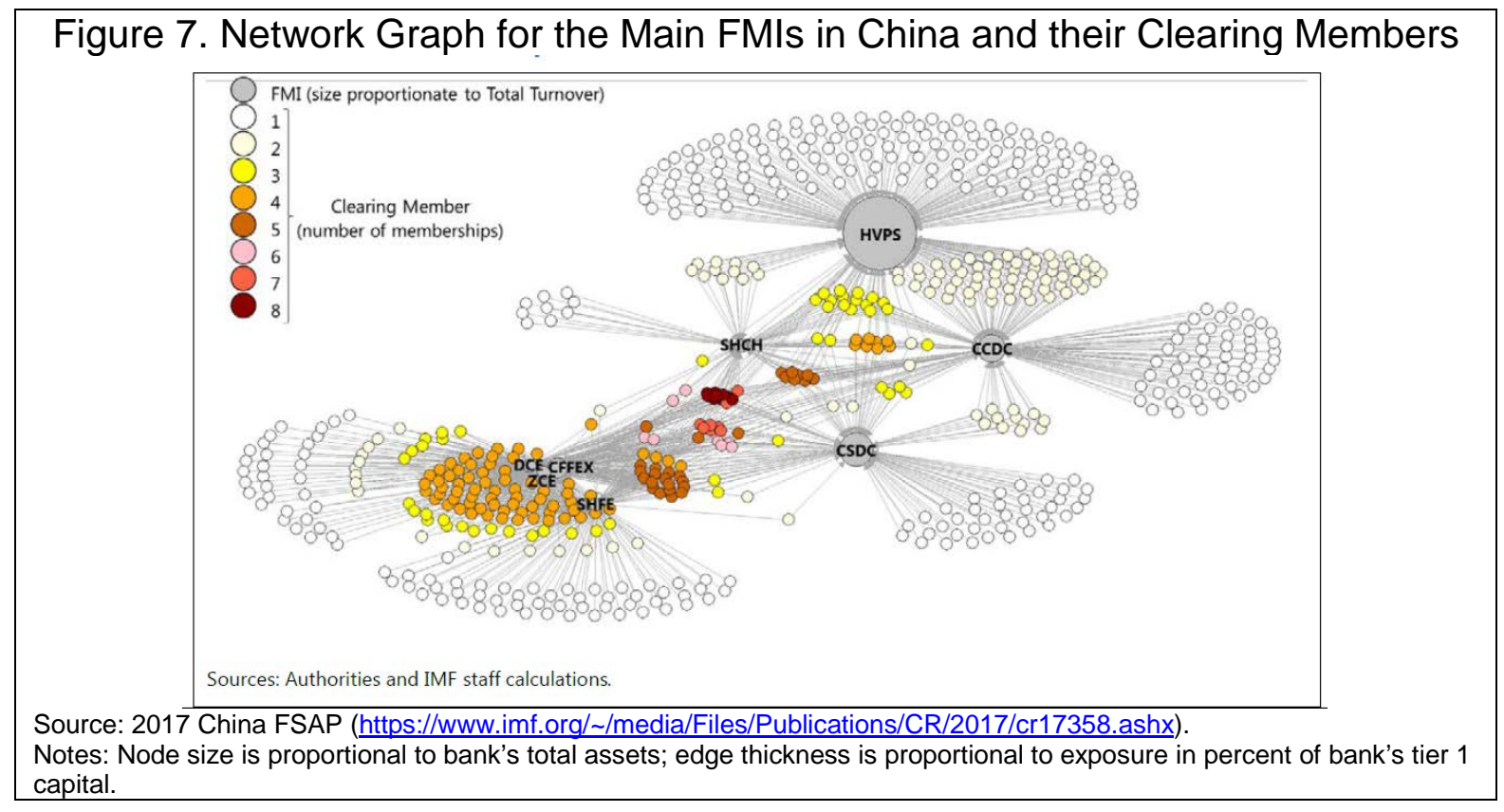




\section{Mapping of Cross-Border Exposures}

On cross-border mapping, the BIS's Consolidated Banking Statistics (CBS) and the Locational Banking Statistics (LBS) provide comprehensive information on banks' foreign exposures. ${ }^{8}$ The CBS report on banks' worldwide consolidated international claims, both on an "immediate borrower" and an "ultimate risk" basis (Figure 8). The latter considers risk transfers, such as hedges and other guarantees. The CBS provides information on the type of exposures by sectors, the extent of pure cross-border claims versus local claims, and the funding patterns for local operations of banks. Detailed information on banks’ local claims and their funding pattern could shed light on banks' international business strategy, such as the subsidiary vs. branch model. On the other hand, the LBS help measure claims and liabilities, including intra-group positions of banking offices residing in reporting countries. LBS data are useful for analyzing the geography of international banking activity and shedding light on the extent of intra-group transfers in cross-border banks. Various studies have used the LBS to analyze banks' role in the transmission of shocks across countries via bank lending and funding channels. ${ }^{9}$

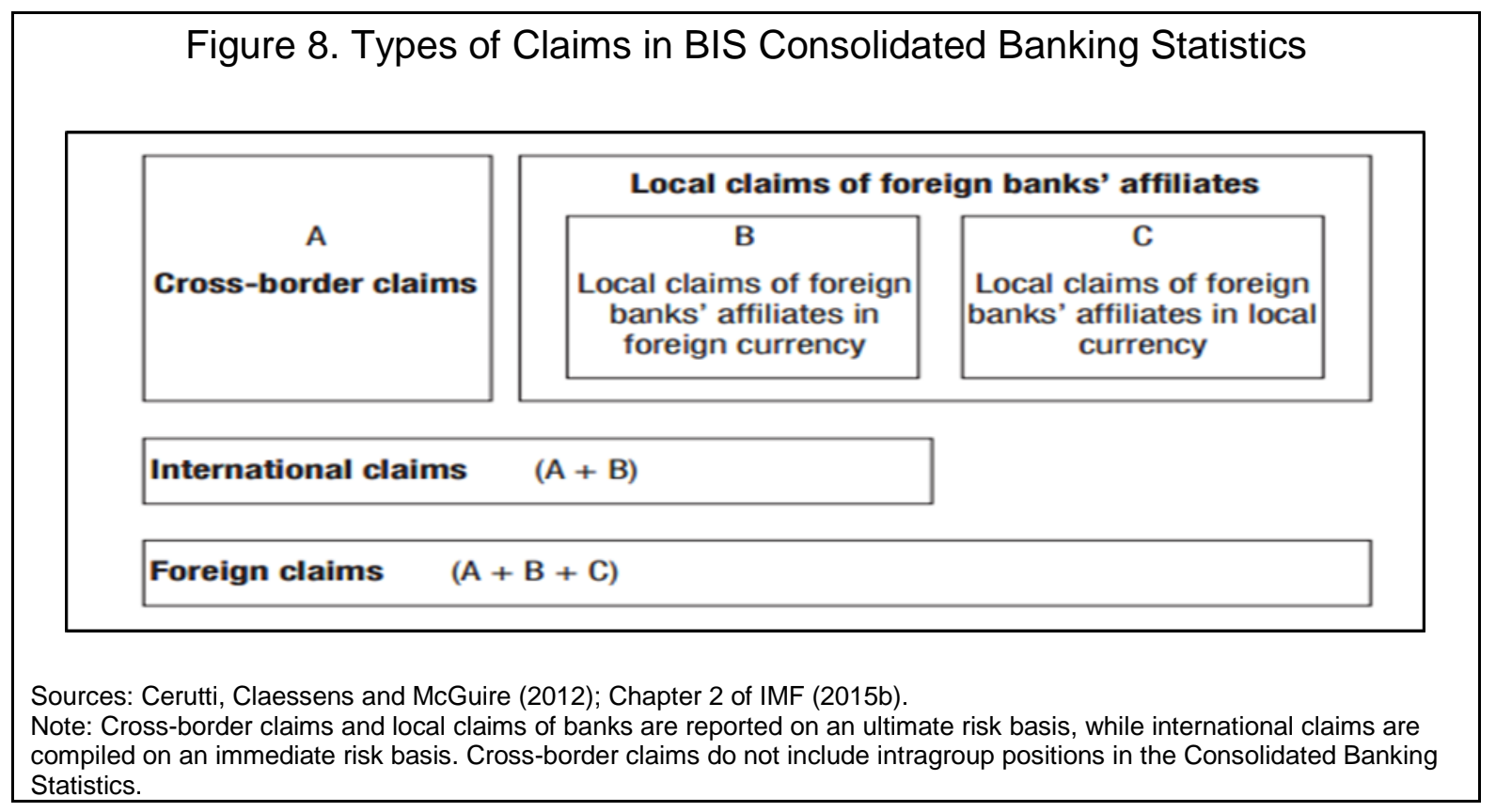

To map the cross-border exposure of a country's banking sector, information on the top destinations and origins of these exposures by country can help identify potential sources of risk transmission and contagion. Understanding the nature of these exposures and the extent to which these claims are against the banking sector, the government sector, or the non-bank private sector, would also be helpful. For example, a high percentage of total claims against

\footnotetext{
8 The LBS data currently cover $93 \%$ of cross-border claims of all banks worldwide. For information on the coverage of CBS and LBS, see https://www.bis.org/statistics/rep_countries.htm.

${ }^{9}$ For example, see BIS (2015). Intra-group refers to business between affiliates of the same corporate group.
} 
the private sector may reflect the "subsidiary" business model of some international banks, instead of the "branch" model, as the "subsidiary" model is often associated with a relatively high share of local funding and lending.

Example: 2017 Spain FSAP. This FSAP provides an example of cross-border mapping using the BIS CBS on an "ultimate risk" basis. Figure 9 shows that most cross-border exposures of Spanish banks are in the United Kingdom, United States, Mexico, Brazil, Turkey, and Chile, where Spanish banks have sizable subsidiary operations. About 70 percent of claims are against the non-bank private sector, while the rest are against the public sector and banks. By origin, the largest foreign claims on Spain are from European countries, namely, France, Germany, Italy, the Netherlands, and the United States. About 40 percent of foreign claims are against the non-bank private sector, while the rest are against the public sector and banks.

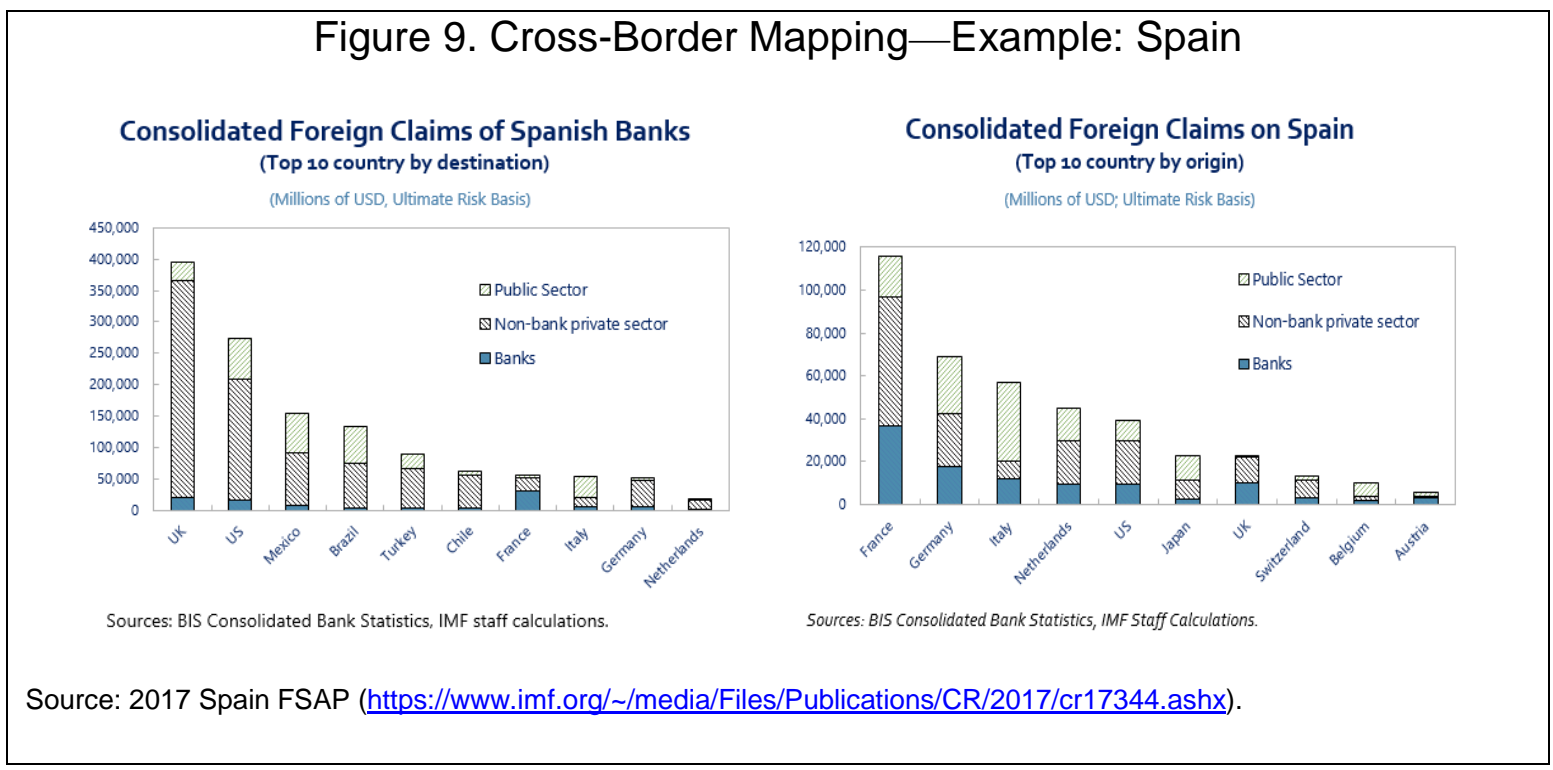

In addition, it would be useful to analyze the business models of international banks through their funding structure and exposures (using the BIS CBS at an immediate counterparty basis). Specifically, it would be important to obtain a breakdown of international claims versus local claims in local currency, as well as the share of local liabilities in local currency. The business models for global banking operations differ substantially among different banking systems. The so-called "international banking” model can be characterized by large cross-border exposures and small local operations, while the "multinational-banking" model or the "subsidiary" model emphasizes local exposures in foreign banking markets (see McCauley, McGuire, and von Peter 2010; Gambacorta and van Rixtel 2013).

Example: 2017 Spain FSAP. In Figure 10 (left), Japanese banks, for example, follow the international banking model, while Spanish banks follow the multinational-banking model or subsidiary model. Also, Spanish subsidiaries exhibit a high degree of funding autonomy, as 
local claims are largely funded by local liabilities in local currency. In contrast, a smaller share of local claims is funded locally for banks headquartered in the United Kingdom and Switzerland.

It is often informative to analyze the evolution of cross-border claims and liabilities, and to understand how they may have changed over time (and the underlying factors driving these changes). Furthermore, it is useful to analyze the stability of bank funding in local currency over time, since it sheds light on potential shifts in risks and business models of these international banks. For example, Figure 10 (right) shows that over time, there is an increase in Spanish banks' foreign exposure, due to a rise in their local claims in local currency. This could be attributed to the expansion of Spanish banks' foreign operations in Latin America, as well as acquisitions in the United Kingdom and Turkey.

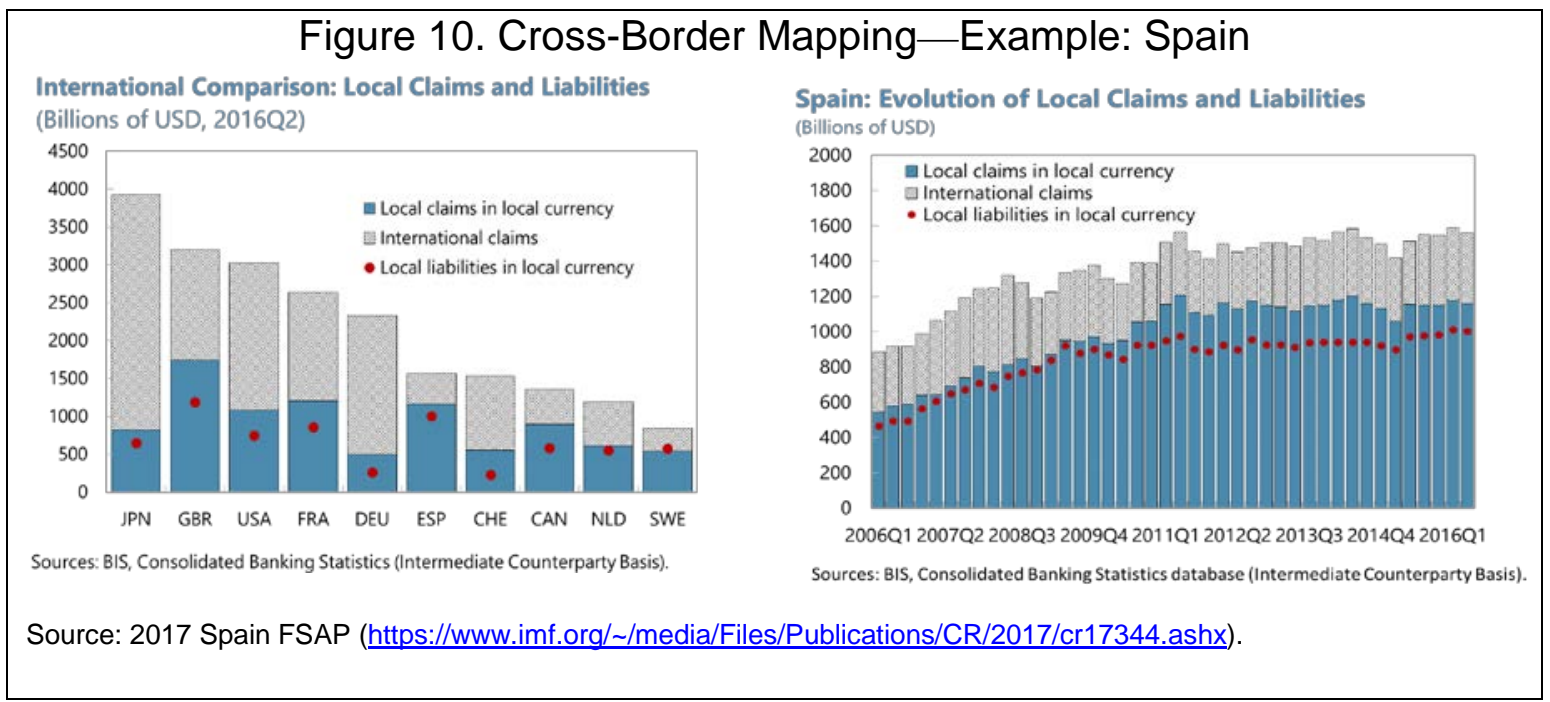

\section{InTERbank, Cross-Sector, ANd Cross-Border Contagion ANalysis (Phase II)}

The analysis of interconnectedness and contagion (Phase II) is usually approached from two angles to capture direct and indirect linkages. It should be noted that indirect linkages can arise from either indirect exposure (e.g., through common asset holding) or from marketbased linkages. To capture both direct and indirect linkages, it is useful to apply (a) exposure or balance sheet data (sometimes supervisory information) to uncover the direct exposure to funding and lending risk or indirect exposure through common exposures and (b) market and financial asset price data to uncover indirect linkages due to market and investor perceptions that are reflected in asset price movements, for example, due to a similarity in business models between entities (Figure 11). ${ }^{10}$ This "dual approach" can be applied to all three strands of the contagion analysis (interbank, cross-sector, and cross-border).

\footnotetext{
${ }^{10}$ In addition to interconnectedness and contagion analysis, solvency and liquidity stress tests examine the role of different funding markets and funding shocks.
} 
Figure 11. Approach to Interconnectedness and Contagion Analysis (Phase II)

\section{Phase II: Analysis or Modeling of Interconnectedness \& Contagion}

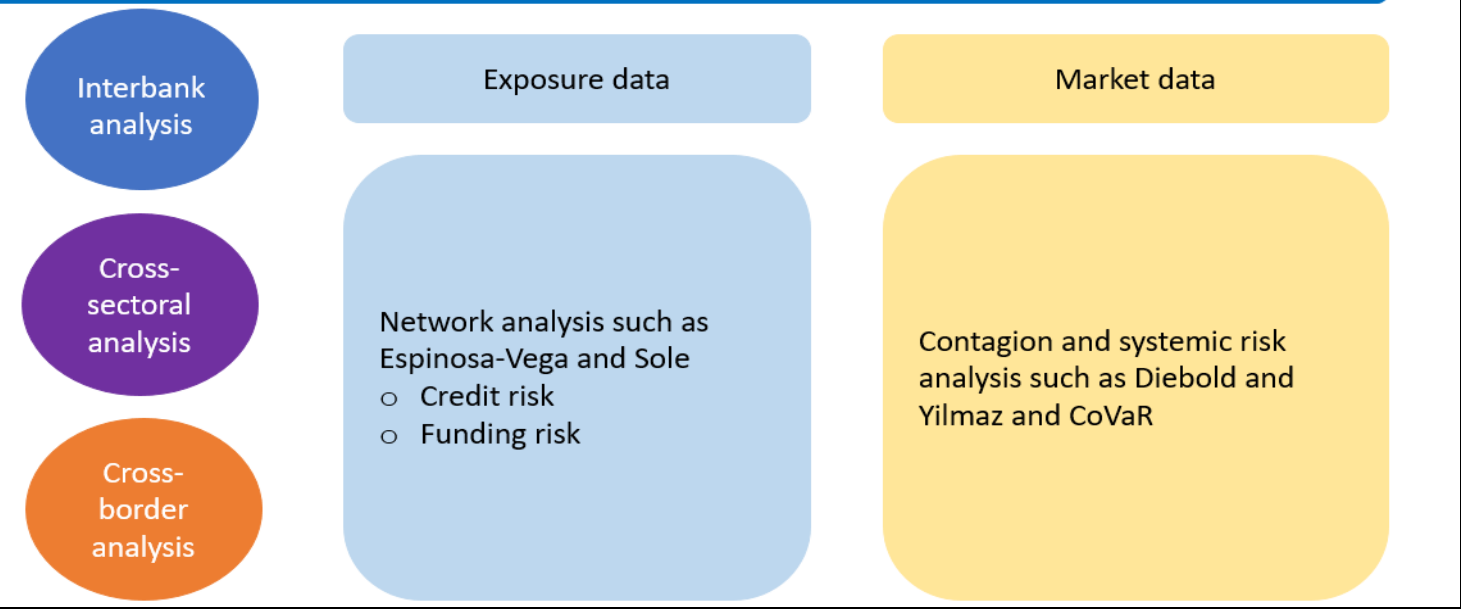

There is a battery of models that work with exposure and market data to analyze contagion. Figure 12 provides an overview and examples of the most commonly-used models for contagion analysis in the FSAP (as well as the GFSR). This overview is by no means complete, but it focuses on the main approaches that have been used in the FSAP in the past five years. Typically, the network approach of Espinosa-Vega and Sole (2010), or some variant, is applied to exposure data. CoVaR and Diebold and Yilmaz (2014) are frequently used market-based approaches. In addition, SyRIN, Systemic CCA, and the Global VAR approaches have been used to analyze interconnectedness and contagion with a combination of exposure and market data. ${ }^{11}$

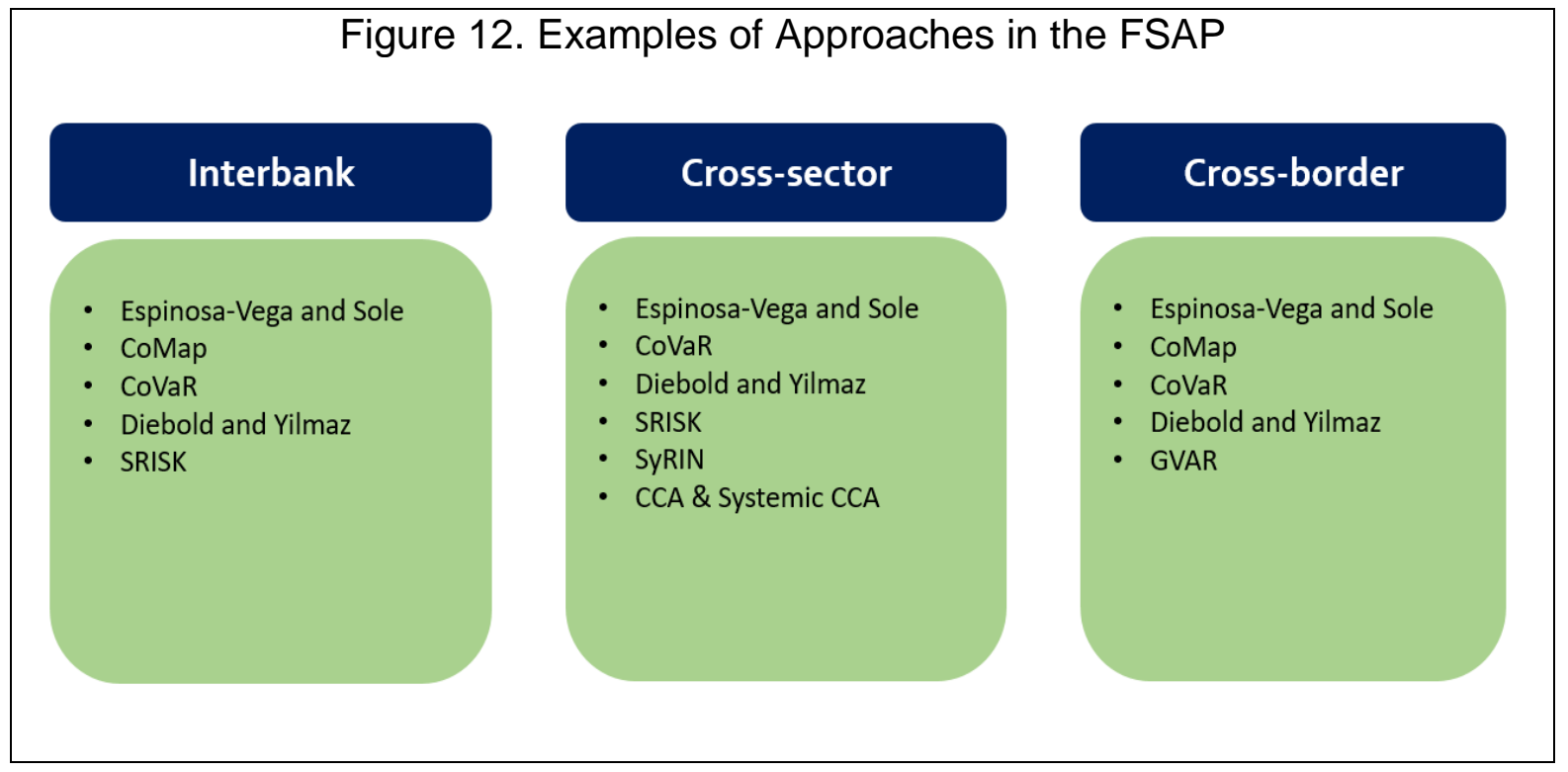

${ }^{11}$ In FSAP, similar models are often applied across countries for consistency and cross-country comparability. 
When should these approaches be applied and under what circumstances? Several of these approaches, including Espinosa-Vega and Sole (2010), CoVaR, and Diebold and Yilmaz (2014) can be applied to all three types of analyses: interbank, cross-sector, and cross-border, as seen in Table 1. Some of the approaches rely on market data-which implies that they are more relevant for emerging markets and advanced economies, but with relatively limited application for low-income countries. The methodologies that rely on exposure data, such as the global VAR, have relatively broad coverage and can be applied to countries with different income levels, to the extent that the relevant data is collected and available. It should be noted that every model has its strengths and weaknesses. Therefore, it is recommended to use more than one model for interconnectedness and contagion analysis and to carry out robustness checks to ensure the consistency of results across approaches.

\section{Table 1. Characteristics of Different Analytical Approaches on Interconnectedness and Contagion Analysis}

\begin{tabular}{|c|c|c|c|c|c|c|c|c|c|}
\hline \multirow[t]{2}{*}{ Approaches } & \multicolumn{3}{|c|}{ Coverage } & \multicolumn{3}{|c|}{ Data applicability } & \multicolumn{3}{|c|}{ Country applicability } \\
\hline & Interbank & Cross-sector & Cross-border & High frequency & Exposure & Market & Low-income & Emerging & Advanced \\
\hline Espinosa-Vega and Sole & $\mathrm{Y}$ & $\mathrm{Y}$ & \begin{tabular}{c|}
$\mathrm{Y}$ \\
\end{tabular} & & Y & & $\mathrm{Y}$ & Y & Y \\
\hline CoMap & Y & $Y$ & $Y$ & & $Y$ & & $Y$ & Y & $\mathrm{Y}$ \\
\hline CoVaR & Y & $Y$ & Y & Y & & Y & & Y & $\mathrm{Y}$ \\
\hline Diebold and Yilmaz & $Y$ & Y & Y & Y & & $\mathrm{Y}$ & & Y & Y \\
\hline SRISK & $Y$ & $Y$ & Y & Y & & Y & & Y & Y \\
\hline SyRIN & & $\mathrm{Y}$ & & Y & Y & $\mathrm{Y}$ & & Y & Y \\
\hline CCA \& Systemic CCA & & $\mathrm{Y}$ & Y & Y & $\mathrm{Y}$ & $\mathrm{Y}$ & & Y & Y \\
\hline Global VAR & & $\mathrm{Y}$ & $Y$ & & $\mathrm{Y}$ & $\mathrm{Y}$ & $Y$ & $\mathrm{Y}$ & $\mathrm{Y}$ \\
\hline
\end{tabular}

Note: The depth of financial markets is also an important consideration of market-based approaches. The Espinosa-Vega and Sole (2010) and the CoMap (contagion mapping) approaches often require confidential supervisory data when used at the entity level.

Next, we provide examples of how these methods can be applied to uncover interbank, crosssector, and cross-border interconnectedness and contagion, and discuss the potential advantages and limitations of some of the approaches.

\section{A. How to Analyze Interbank Interconnectedness and Contagion?}

For interbank contagion analysis based on direct exposure data (usually obtained through supervisory agencies), a network approach like Espinosa-Vega and Sole (2010) (EVS) is a good method to start with. This network model examines interbank exposures by tracing the implications of credit and funding shocks to the financial entities in the sample. Credit shocks are analyzed through the "failure" of entity A and its incurred credit losses to entity B (and other entities in the sample) that have claims against A. Funding shocks are analyzed through the implications of a "failure" of entity A and how it will force entity B (that has liabilities with A) to find alternative sources of funding. The algorithm tracks the implications of a "failure" through several rounds until no failures occur (see Figure 13). 


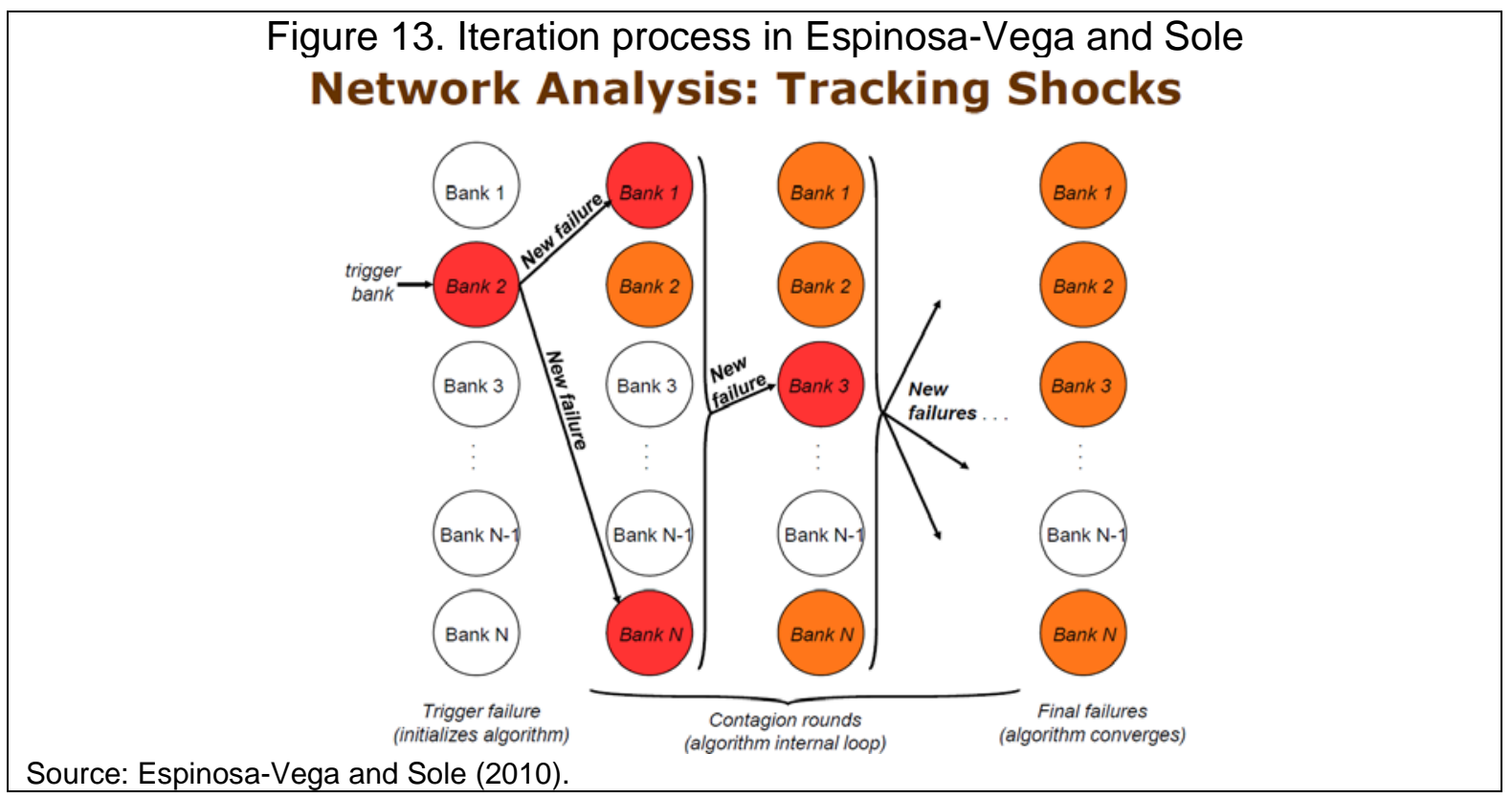

Example: 2017 Luxembourg FSAP. Figure 14 shows results for the contagion index and the vulnerability index as calculated by the EVS model for Luxembourg's interbank market. The contagion index identifies the most contagious entities-banks that would yield the highest average losses across all other banks in the sample, based on credit and funding shocks. The vulnerability index identifies banks that are most vulnerable to defaults from other banks in the sample by calculating the average loss a bank would incur across individually triggered failures. In Luxembourg, domestic interbank positions are found to be small, especially compared to banks' capitalization. For each of the sixteen banks in the sample, the total gross exposures to the other fifteen banks are smaller than its regulatory capital. Therefore, no single failure of a domestic bank would trigger the failure of another bank, and thus no "cascade effect" would take place in this representative sample. Thus, the aggregated EVS's indices of contagion and vulnerability are low. The entity with the highest contagion index, bank 11, causes losses of less than 0.4 percent of counterparties' capital (Figure 14, left) with the entity most adversely impacted, bank 11, incurring losses of less than 1.2 percent of its capital (Figure 14, right). 


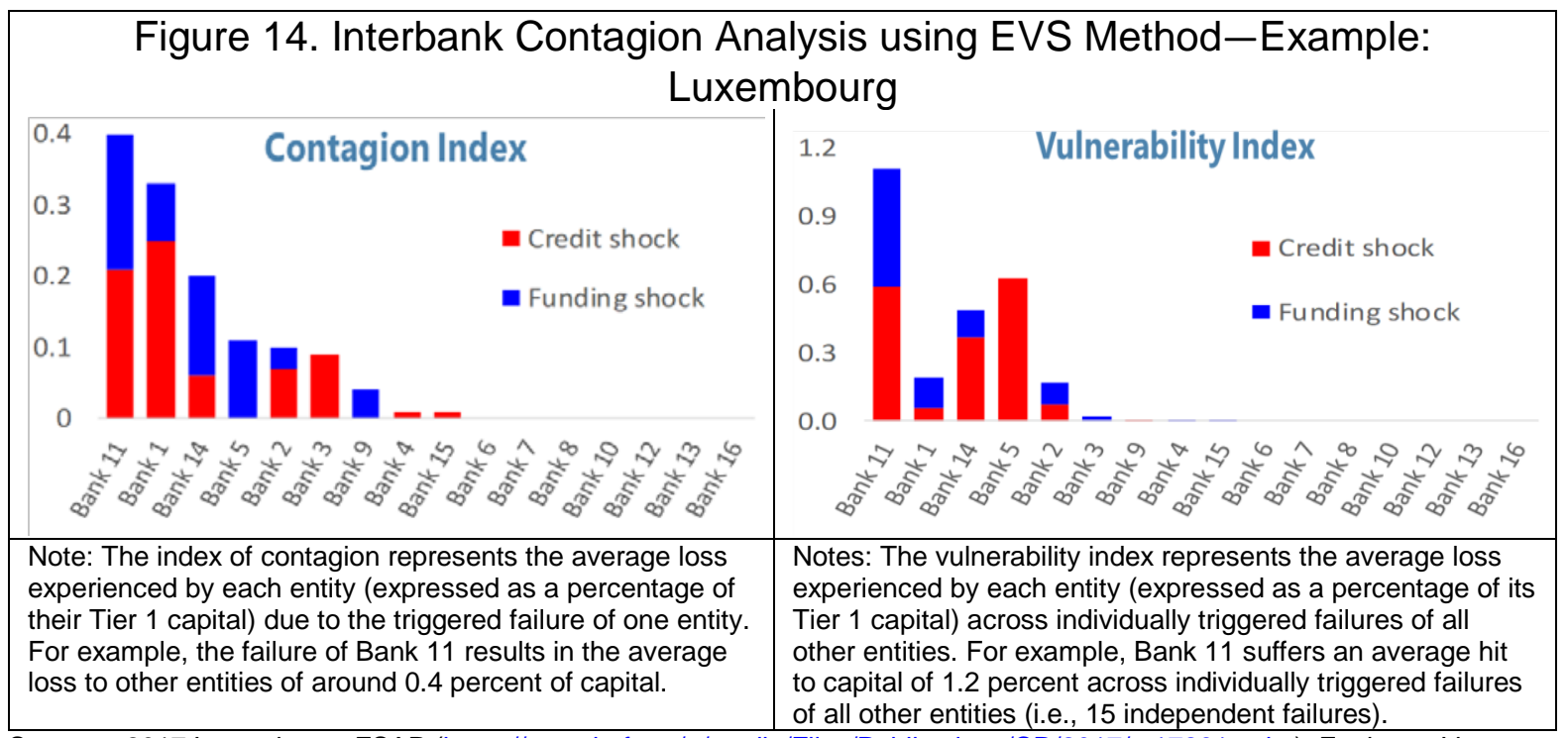

Sources: 2017 Luxembourg FSAP (https://www.imf.org/ /media/Files/Publications/CR/2017/cr17261.ashx); Espinosa-Vega and Sole (2010) and IMF staff calculations.

As with every method, the EVS approach has some limitations. For instance, model parameters (e.g., loss given default, the fraction of funding lost, probabilities of default) are usually preset in the model, and some of the assumptions could be overly simplistic and disconnected from the adverse scenario in the solvency stress test. ${ }^{12}$ However, it is possible to vary the loss given default ratio to carry out sensitivity checks (see 2017 Luxembourg FSAP Technical note on risk analysis).

To address some of the shortcoming of the EVS, Covi, Gorpe, and Kok (2019) developed a contagion mapping (CoMap) methodology and applied it in the context of the Euro Area FSAP. The CoMap methodology estimates contagion potential due to credit and funding risks via bilateral linkages. The main objective is to assess the amount of losses and number of defaults an exogenous shock to a bank induces to the system. In achieving this, the CoMap methodology evaluates first-round effects (direct losses) and subsequent-round effects (indirect losses) due to cascading defaults and potential fire-sale losses. To apply more realistic assumptions, the authors allow for variations in: (i) bank-specific default thresholds, such as minimum capital requirements and capital buffers; (ii) changes to the network structure via large exposure limits; (iii) variations in exposures at risk (loss-given-default); (iv) changes in the maturity structure of bank funding; (v) market risks linked to a bank's business model captured by the amount of financial assets and high quality liquid assets (HQLA) on a bank's balance sheet; and (vi) changes in bank-specific liquidity coverage ratios due to adjustments in liquidity buffers and/or the net liquidity outflows. As a result, this framework can capture the risk-return trade off a bank faces between holding HQLA and

\footnotetext{
${ }^{12}$ For instance, EVS is based on point in time data. In case of a funding shock, it is assumed that loans borrowed by entity B from entity A are due when entity A defaults. However, the failing of lending entity A does not necessarily lead to a direct loss of funding for borrowing entity B, unless the loan for entity B is due when lending entity A fails.
} 
non-HQLA financial assets and allows for assessing both solvency and liquidity risk while accounting for bank-specific parameters. Finally, the CoMap approach incorporates (vii) liquidity constraints on the amount of assets available for sale, allowing a bank to default due to illiquidity.

Example: 2018 Euro Area FSAP. ${ }^{13}$ Using the CoMap approach, this FSAP examines contagion risk stemming from credit and funding shocks and considers a wide range of parameters for sensitivity checks. It found that even under more extreme assumptions applied to the intra-euro area network, only one bank would face acute distress (Figure 15, left). This reaffirmed the resilience of the network to interbank contagion. In contrast, the larger global cross-border network was found to be more sensitive to changes in model parameters and assumptions (Figure 15, right). For example, increasing the loss given default parameter (from 60 percent to 80 percent) and raising the funding shortfall ratio (from 50 percent to 65 percent) would lead to more than twice the number of acute distresses in the global network.

\section{Figure 15. Bank Distress Sensitivity to Model Assumptions-Example: Euro Area}

Heatmap of Bank Distress in Intra-EA Network

(Number of distressed banks in each simulation)

capital buffer:

CET1 surplus

loss given default

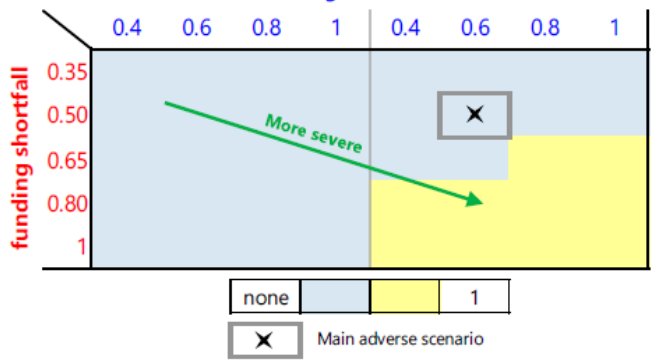

Heatmap of Bank Distress in Global Network

(Number of distressed banks in each simulation)

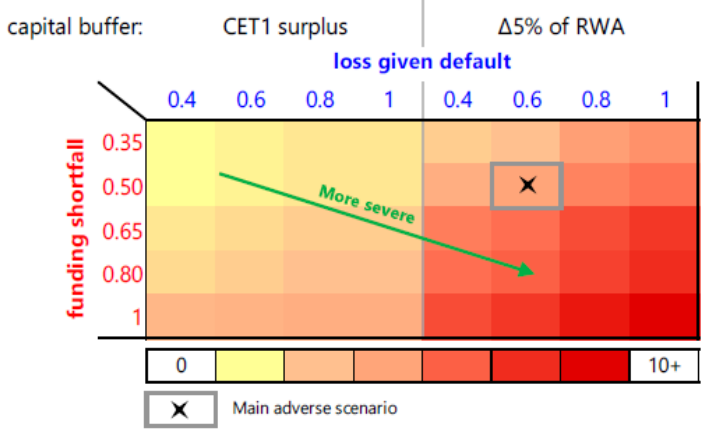

Sources: ECB, and IMF staff calculations.

Sources: 2018 Euro Area FSAP (https://www.imf.org/ /media/Files/Publications/CR/2018/cr18231.ashx); European Central Bank; IMF staff calculations.

In addition to methodologies based on exposure data, market-based approaches can be used to uncover indirect linkages due to market and investor perceptions that are reflected in asset price movements. One method for teasing out indirect interconnectedness across banks is the approach proposed by Diebold and Yilmaz (2014) (D-Y). The authors use equity returns and/or return volatility data ${ }^{14}$ to examine the interlinkages between publicly traded financial

${ }^{13}$ The 2019 Malta FSAP is another example where the CoMap methodology was applied.

${ }^{14}$ In Diebold and Yilmaz (2014), the authors calculate daily realized volatilities as the sum of squared log price changes over 78 five-minute intervals during trading hours from 9am-12pm and 1pm-4:30pm. If intraday data is not available, daily volatility can be computed using the opening and close price as well as the highest and lowest daily quotes. 
entities (FEs). They argue that asset returns reflect changes in investor expectations, while asset return volatilities reflect investor fear. ${ }^{15}$

The D-Y approach begins by first estimating a Vector Autoregression (VAR) model with market data. The interconnectedness measure is then derived from the Generalized Variance Decomposition (Pesaran and Shin 1998) of the underlying VAR (Figure 16). ${ }^{16}$ The "toindex" captures contributions of individual firms to systemic network events (outward spillover). The "from-index" captures exposures of individual firms to systemic shocks from the network (inward spillover). The "net-index" (the difference between to- and frommeasures) describes the relative contribution to systemic risks from each financial firm. The "total connectedness index" shows the total (system-wide) connectedness for all entities in the sample. Using rolling window estimations, this measure can be computed for each observation period. This allows for the monitoring of total connectedness over time.

The D-Y approach links variance-decomposition in VARs and network topology by recognizing that variance decompositions of VARs form networks. For the estimation of large-scale VARs (more than 30 variables), it is useful to apply a shrinkage technique (LASSO) in the application of the D-Y methodology, following Demirer and others (2018). In addition, the shrinkage technique allows for shorter estimation periods, which may be relevant for structural identifications in event studies. ${ }^{17}$ When applying D-Y, it is useful to carry out robustness checks by including exogenous factors (e.g., global financial conditions, the VIX, or commodity prices) and to pre-filter common factors from asset returns. This would be in addition to changing the estimation window (e.g., from 200 to 150 days) and varying the lag orders and the forecast horizons. ${ }^{18}$

\footnotetext{
${ }^{15}$ Market data other than equity prices can be employed in this methodology as well, potentially unveiling different channels. For instance, bond spreads and currency returns were employed to measure spillovers from emerging markets to advanced economies in IMF (2016).

${ }^{16}$ In contrast to the traditional Cholesky and other structural identification strategies, the Generalized Variance Decomposition does not impose any assumptions on the order of variables. Instead, it relies on a largely databased identification scheme (it "lets the data speak").

${ }^{17}$ A shrinkage technique (LASSO) following Demirer and others (2018) was incorporated in the application of the D-Y approach in recent FSAP.

${ }^{18}$ For an example on how these robustness check could be done see also Malik and Xu (2017).
} 


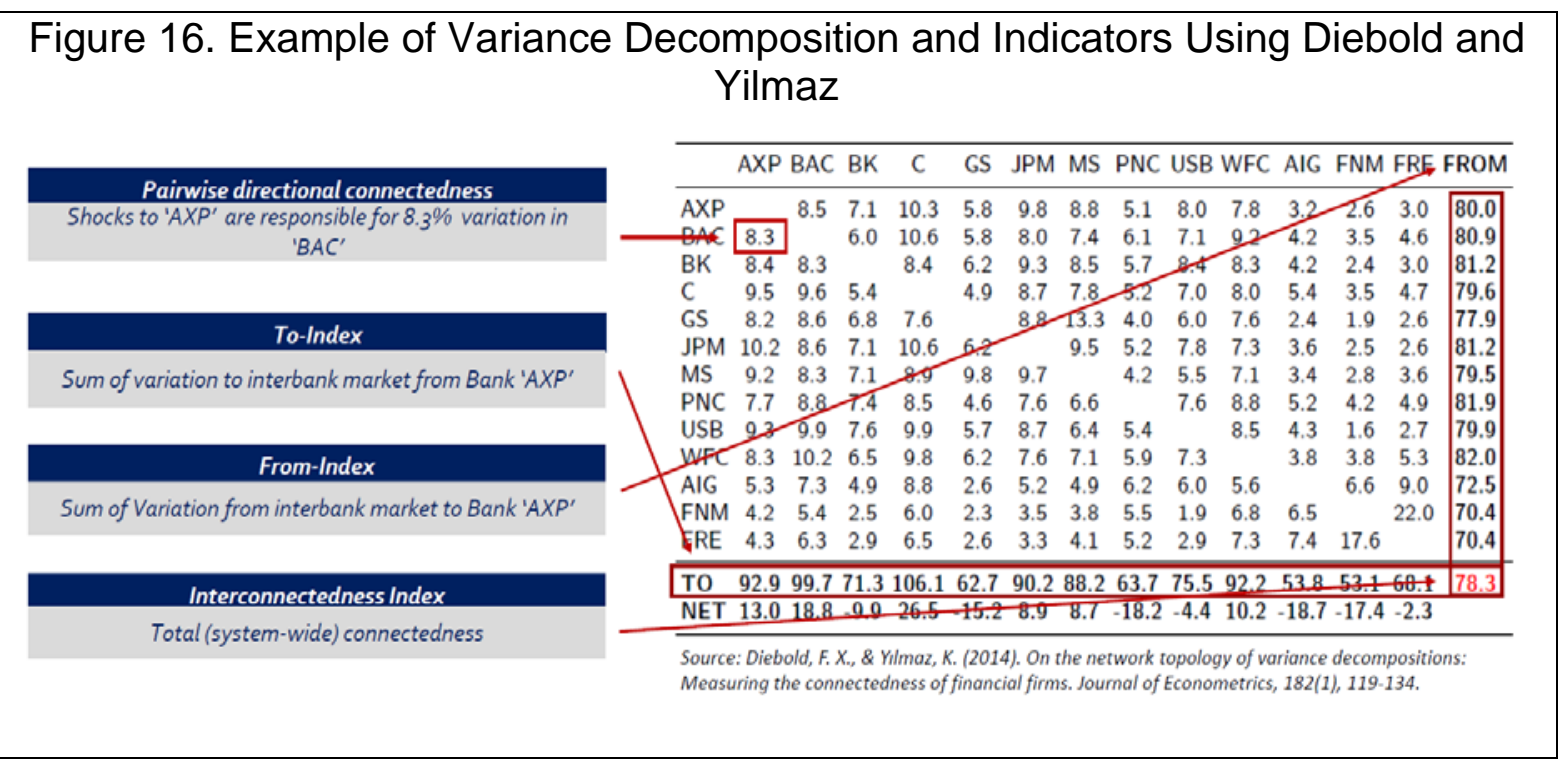

Another market-based alternative (or complement) to the D-Y method is SyRIN, developed by Segoviano and Goodhart (2009) and Cortes and others (2018). This method, like D-Y, can be used to examine not only interbank connectedness, but also cross-sector and cross-country linkages, provided that an appropriate financial market price/index is found to be a good proxy for a given sector or country (more on this below). In SyRIN, the financial system is conceptualized as a portfolio of financial entities (FEs) spanning different sectors. A structural approach for modeling portfolio risk ${ }^{19}$ is used to derive "probabilities of distress" (PoD) for each entity. ${ }^{20}$ Taking each estimated PoD as inputs, a portfolio multivariate density describing the joint likelihood of distress of all FEs in the system can be derived. PoDs are a crucial input in this method and can be based on data from equity prices, credit default swap (CDS) spreads, bond yields, and out-of-the-money option prices_or estimated using supervisory information. This is an advantage in cases where equity prices for certain entities (e.g., state-owned banks, subsidiaries of banks, and investment funds) are not available.

SyRIN allows for the computation of several informative measures of systemic risk and interconnectedness. First, a joint probability of distress (JPoD) measure describes the likelihood that all FEs in the portfolio/system are in distress. Second, a Financial Stability

\footnotetext{
${ }^{19}$ The structural approach is normally used to measure credit risk in portfolios of loans. In this exercise the approach is used to measure risk in a portfolio of FEs across sectors. Well known applications of the structural approach include the Credit Metrics framework (Gupton, Finger, and Bhatia 1997) and the KMV framework (Crosbie and Bohn 2003).

${ }^{20}$ Under this approach, a change in the value of a borrower's assets is related to the change in its credit risk quality. The basic premise of the structural approach is that a borrowing entity's underlying asset value evolves stochastically over time, and distress is triggered by a drop in the firm's asset value below a threshold value (distress/default region), the latter being modeled as a function of the FE's financial structure. Thus, it follows that the likelihood of the entity's asset value falling below the distress threshold is represented by the probability of distress of the entity.
} 
Index reflects the expected number of FEs that may become distressed if at least one bank becomes distressed. Third, a Distress Dependence Matrix reports the probability of an entity specified in one row falling into distress should an entity specified in the column be in distress. ${ }^{21}$ The probability that at least one FE becomes distressed characterizes the likelihood that one, two, or more institutions (up to the total number of FEs in the system) become distressed, thereby, quantifying potential "cascade" effects. Fourth, a Tail Risk Index uses the "systemic" expected shortfall, which can be computed at each point in time, and sets it in reference to the highest expected shortfall. It therefore tracks the relative position of systemic risk regarding a set reference point (usually a financial crisis).

Example: 2017 Luxembourg FSAP. SyRIN was applied here because it offered the advantage of working with bond yield data to derive PoDs for bank subsidiaries. Since many banks in Luxembourg are subsidiaries of larger foreign banks, there are no explicit equity prices available for these subsidiaries. However, four of these subsidiaries issued bonds, which enabled the computation of PoDs. These were then be used in the SyRIN framework. This FSAP shows that financial distress in Luxembourg subsidiaries has decreased since the European debt crisis (Figure 17).

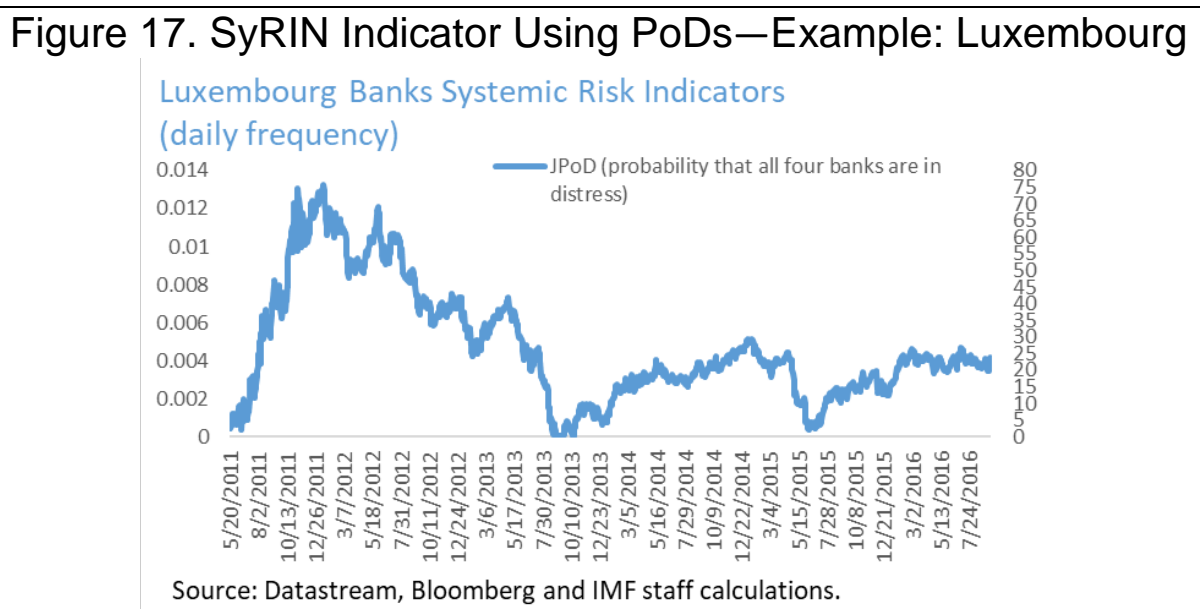

Source: 2017 Luxembourg FSAP, available at https://www.imf.org/ /media/Files/Publications/CR/2017/cr17261.ashx. Note: JPod $=$ joint probability of distress.

One caveat with market-based methodologies is that the application and results depend on the availability and the quality of market data. For example, the application of market-based approaches in low-income countries could be relatively limited. The same is true for financial systems with large state-owned companies, those with subsidiaries of bank that don't trade on stock exchanges, or those with low trading volume. In addition, most market-based models are not structural and therefore cannot identify the source of contagion. Asset prices

\footnotetext{
${ }^{21}$ While conditional probabilities do not necessarily imply causation, it is worth noting that pair-wise conditional probabilities can provide important insights into interconnectedness between FEs and/or sectors constituting the system.
} 
could be exhibiting strong co-movements due to common factors that may or may not arise from connectedness, or fully reflect financial sector fundamentals. Therefore, it would be useful to cross-check the results from market-based approaches with those of exposure-based approaches.

\section{Integration with Solvency Stress Testing for Feedback Effects}

To capture the impact of second round feedback effects through interbank contagion, it is useful to combine interbank contagion analysis with bank solvency stress tests. One approach to integration uses the results of the solvency stress tests (e.g., the banks with capital shortfalls) as the starting point for the interbank contagion analysis. To ensure consistency between the interbank contagion analysis and solvency stress tests, one should ideally use the same sample of banks in both analyses.

For example, the "Stress Tester" tool by Čihák (2007) incorporates a matrix of interbank exposures and two versions of contagion-one triggered by ad-hoc failures and one linked to a macro scenario. This tool has been used in FSAP and IMF technical assistance and by authorities in low-income countries.

The integration of interbank analysis and stress testing was recently considered in the 2017 Indonesia FSAP and the 2019 Poland FSAP. After the first year of the solvency stress tests, pre-contagion capital positions and information on banks in distress (i.e., those that breached a certain hurdle rate) were used as a starting point for the EVS interbank model. Next, the EVS framework was run assuming the default of interbank exposures for the bank(s) that didn't meet the hurdle rate from the solvency stress tests. The EVS methodology then estimated the impact of default of interbank exposures for post-contagion capital positions, which were used as a starting point for the second-year of the solvency stress test. This iteration repeated for each year of the stress scenario.

Example: 2017 Indonesia FSAP. This FSAP provides an example of integrated solvency and interbank contagion analysis (Figure 18). At the end of the stress testing horizon, the impact of interbank contagion was found to be about 0.5 percentage points (in terms of riskweighted assets). The results suggest that the interbank contagion effect is relatively low in Indonesia as interbank linkages are limited. 


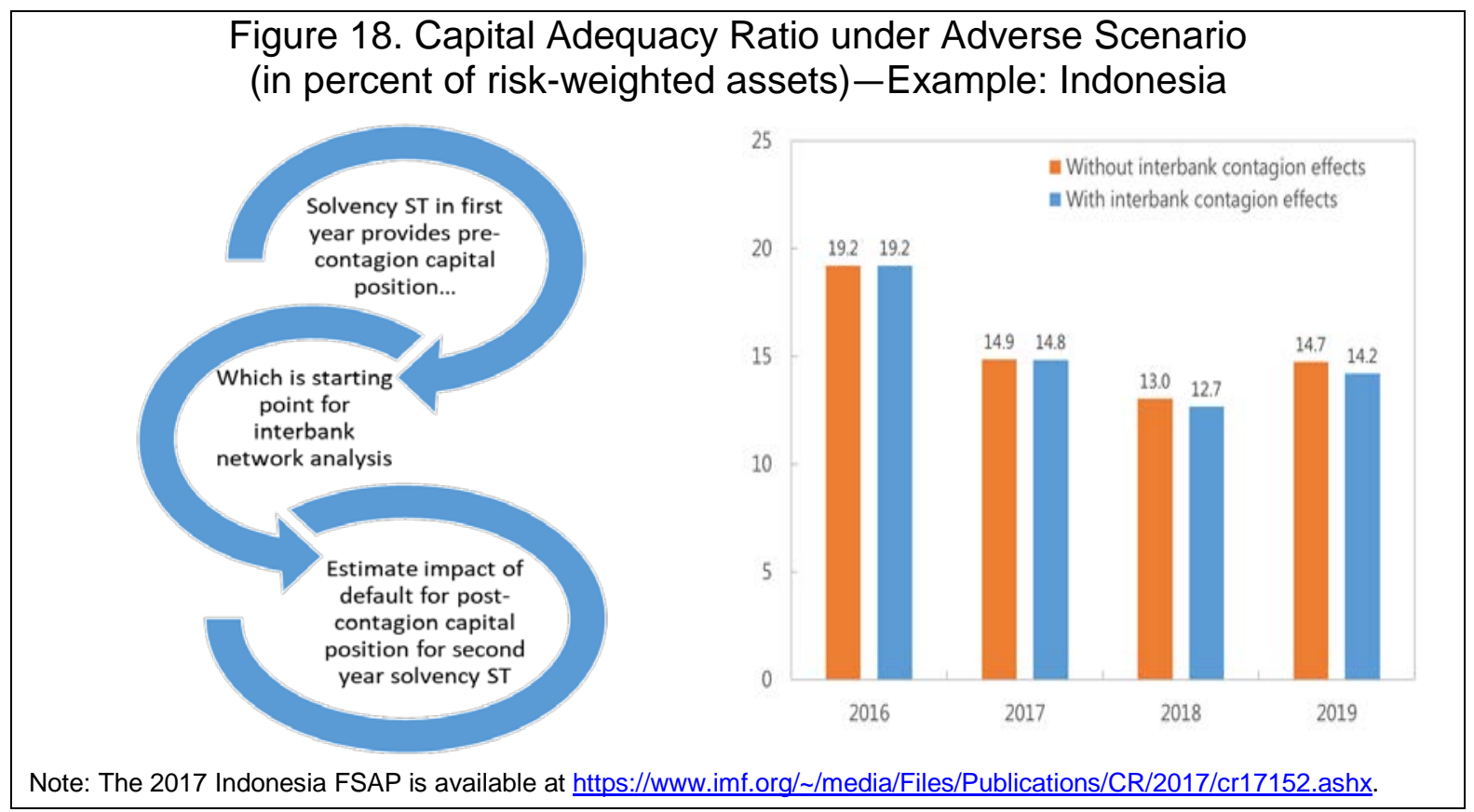

One potential limitation of the EVS approach is that it does not account for the effects of fire sales on common (indirect) exposures that are typically observed in second round effects, but instead focuses on direct interbank exposures. An alternative approach was recently developed by various central banks, including Bank of Canada’s Macro Financial Risk Assessment Framework, which links stress testing results and assumptions with the interbank contagion model and embeds second round effects. ${ }^{22}$

\section{B. How to Analyze Cross-Sectoral Interconnectedness and Contagion?}

The second part of Phase II is cross-sectoral analysis. An important cross-sectoral link in many countries is the bank-insurance nexus. This link, as in interbank analysis, can be explored from two angles using (i) direct exposure data (usually supervisory information) and (ii) market data. To analyze direct exposure, the EVS methodology offers a useful start to explore the contagion between banks and insurers (as described above).

Example: 2017 Luxembourg FSAP. In Luxembourg, both the banking and insurance sectors are large, and insurers tend to hold substantial deposits with banks, which is the motivating factor for an in-depth cross-sectoral analysis. Figure 19 shows the results of this 2017 analysis, which suggest that, under a very severe scenario involving 27 independent failures, banks generally appear more contagious than insurance companies, while insurance companies are found to be more vulnerable.

\footnotetext{
${ }^{22}$ See Fique (2017).
} 


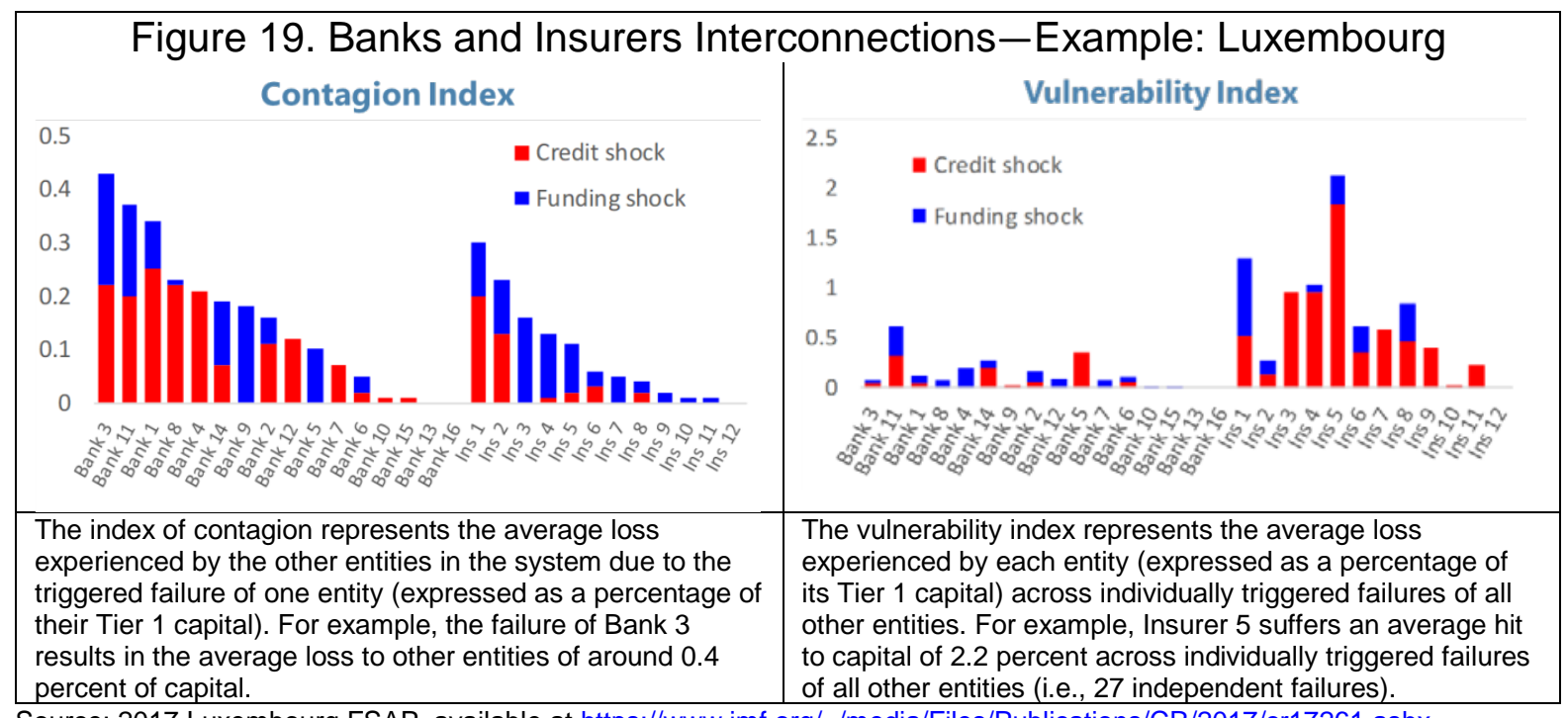

Source: 2017 Luxembourg FSAP, available at https://www.imf.org/ /media/Files/Publications/CR/2017/cr17261.ashx.

To analyze indirect linkages between banks and insurers or any other sectors, one could start from the D-Y approach using market data. Like interbank analysis, the input data for the D-Y methodology could be equity returns, intra-day volatility, bond yields, or CDS spreads. In addition to interconnectedness in the financial sector, the D-Y approach can be used to explore indirect linkages between the financial sector, non-financial sectors, and the sovereign, shedding light on market perception of cross-sectoral macro-financial relations.

Example: 2017 Finland FSAP. This FSAP used equity indexes to analyze interconnectedness between banks, insurers, and other non-financial sectors (see Figure 20). The results show that Finnish banks share strong linkages/spillovers with insurers, and that more moderate linkages exist between banks and the central government. In addition, Figure 20 shows that Finland's non-financial sector is strongly inter-connected, notably in the technology and goods sectors.

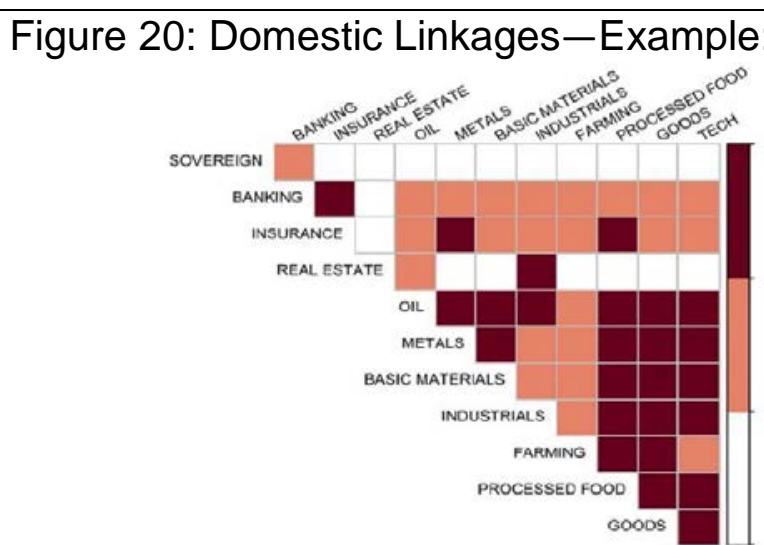

Source: 2017 Finland FSAP (https://www.imf.org/ /media/Files/Publications/CR/2017/cr1706.ashx).

Notes: Chart shows the intensity of total (to and from) implicit financial linkages between the sectors of the Finnish domestic economy. Linkages are estimated using sector-specific equity indexes for each country and span the period of 2010-16Q1.

Colors denote linkage strength, as measured in quantiles. White $=$ bottom $1 / 3$ of all linkages; pink $=$ middle $1 / 3$ of all linkages, and red $=$ top $1 / 3$ of all linkages. 
Another approach to capture the interconnectedness among banks, insurers, and investment funds is the SyRIN methodology. SyRIN computes the probabilities of distress (PoD), which can be based on CDS spreads, bond prices, and balance sheet data. This is especially helpful when equity data is not available, which is the case for investment funds. In countries where investment funds play an important role, as is the case in Luxembourg (which has the second largest investment fund industry in the world after the U.S.), the complimentary application of SyRIN was necessary to analyze this part of the financial sector. To derive the PoD for investment funds, it is necessary to obtain the following supervisory data: (i) total net assets, (ii) subscriptions, and (iii) redemptions. Ideally the data is of daily or monthly frequency. The PoDs for investment funds can be derived by linking investment funds' returns (changes in total net assets) to their outflows (i.e., redemption risk). The intuition is that when investment funds experience strong outflows (exceeding their cash holdings), they are likely to sell their assets to meet these redemption demands, which would put them in a position of distress. Furthermore, their asset sales could have a market impact, thereby indirectly affecting other institutions holding the same assets (common exposures), and potentially leading to contagion risk through fire sales. To analyze possible interlinkages between banks and investment funds, PoDs derived for banks (using bond spreads) and investment funds (using supervisory data) could be combined and serve as inputs for both the SyRIN and the D-Y frameworks.

Example: 2017 Luxembourg FSAP. Authorities in Luxembourg provided detailed data on different classes of funds: bond, emerging markets, high yield, mixed, money market, and variable net asset value money market. To derive the PoDs, returns on assets were estimated using monthly mark-to-market data (i.e., changes in total net assets). Before calculating the return on assets, the total net assets were adjusted by monthly redemptions and subscriptions to derive the "pure" change in assets caused only by changes in prices and not by changes in volumes. Then, over a 12-month rolling window, the number of times returns fell below a specific threshold were summed-up and divided by the number of observations to get the PoD. PoDs were derived using several thresholds, and the $5^{\text {th }}$ percentile threshold of the overall distribution of returns was found to be most reasonable. As seen in Figure 21 (left), PoDs at the $5^{\text {th }}$ percentile reflected the increased risks during the global financial crisis and European debt crisis. The resulting variance-decomposition network using these PoDs in the D-Y approach was visualized using Gephi (see Figure 21, right). It shows that bond and mixed funds are the most interconnected in Luxembourg and there are only a few connections to Luxembourg banks (albeit the coverage of the banking sector is limited to only four banks and needs to be interpreted in that context ${ }^{23}$ ).

\footnotetext{
${ }^{23}$ Note that the analysis of the financial sector in Luxembourg (based on solvency and liquidity stress test as well as contagion and interconnectedness analysis) concluded that its "financial system's ability to withstand severe but plausible shocks suggests a good deal of resilience, albeit with some risks” (Luxembourg FSAP 2017).
} 
Figure 21. Probability of Distress for Investment Funds-Example: Luxembourg

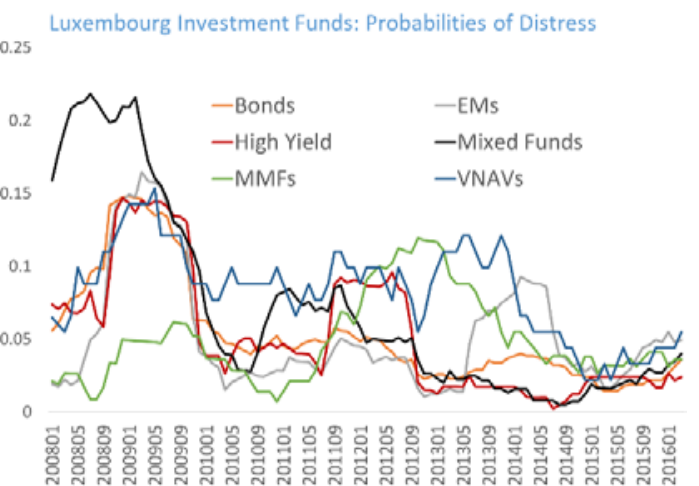

Luxembourg: Domestic Bank-Fund Network Graph based on Market Data (2011-2016)

Sources: 2017 Luxembourg FSAP (https://www.imf.org/ /media/Files/Publications/CR/2017/cr17261.ashx); Luxembourg authorities; and IMF staff calculations. Figure right: Edge thickness and darkness shows the strength of the pairwise relationship. Node size indicates total asset size; color of nodes indicates "total connectedness to others," with dark red indicating strongest connections with other entities in the sample. Node location is derived using ForceAtlas 2 algorithm..

SRISK is another option for deriving systemic risk indicators across sectors (and in the interbank market). Developed by Acharya, Engle, and Richardson (2012), SRISK is defined as the capital that a firm/financial system is expected to need in a financial crisis. SRISK is based on debt, equity values, and the Marginal Expected Shortfall (MES). While debt and equity values can be readily available, the estimation of the MES requires the introduction of appropriate time series techniques. The specification is characterized by time varying volatility and correlation. ${ }^{24}$

Example: 2016 United Kingdom FSAP. SRISK and SyRIN's Tail Risk Index were applied in this FSAP to measure systemic risk in the banking and insurance sectors (see Figure 22). Results showed that systemic risk has been on the decline since the Global Financial Crisis.

Figure 22. Systemic Risk in the Banks Insurers-Example: United Kingdom

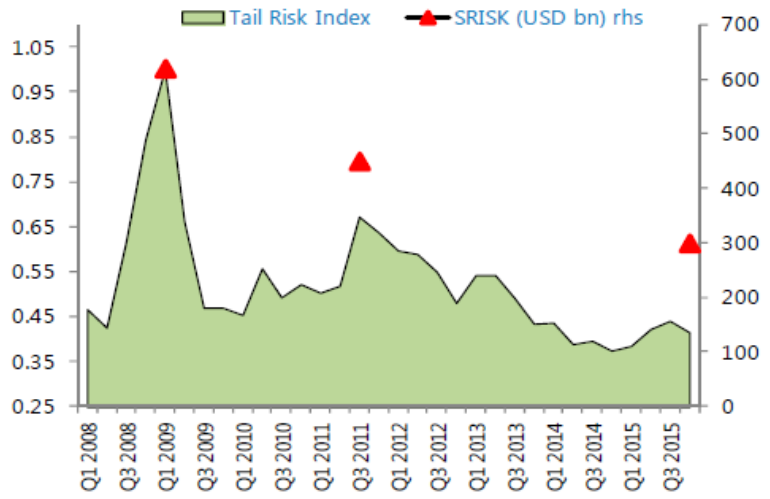

Source: 2016 United Kingdom FSAP (https://www.imf.org/external/pubs/ft/scr/2016/cr16164.pdf).

Note: The Tail Risk Index measures the expected shortfall from the system's simulated portfolio loss distribution, normalized by the historical maximum reached during the global financial crisis. This measure is bounded between zero and unity. SRISK measures the expected capital shortfall of the financial system if equity values were to decline to crisis levels.

${ }^{24}$ For countries with advanced equity and capital markets, the SRISK indicator can be easily obtained from the V-lab website: https://vlab.stern.nyu.edu/en/welcome/risk/ 
Concentration in funding sources across sectors could be another source of contagion in crisis times. For example, commercial paper markets and asset-backed securities have played an important role in many advanced economies, especially during crisis times. Therefore, it is highly relevant to identify key markets where contagion could trigger a full-fledged systemic event. The analysis of funding sources is often done in the context of solvency and liquidity stress tests, which examine the role of different funding markets and funding shocks. If data is available, it would be informative to analyze the interconnectedness of market participants through funding sources and payment systems.

Example: 2018 Jamaica FSAP. In this FSAP, authorities provided access to real-time gross settlement data to infer direct connections among 26 participants. The data allowed the FSAP team to differentiate among seven different payment/funding sources. The network analysis in Figure 23 shows that four deposit taking institutions are important to the large value payment system, accounting for about half of the transactions. If any of these four institutions were to fail to participate in the large-value payment system, liquidity and asset exchanges among financial institutions and operations in the real sector could be extensively affected.

Figure 23. Large-value Payment System Network Analysis-Example: Jamaica A. Four DTIs appear to be central in the large-value payment system network...

... B. three DTIs, actively borrow from BoJ's short-term repos.
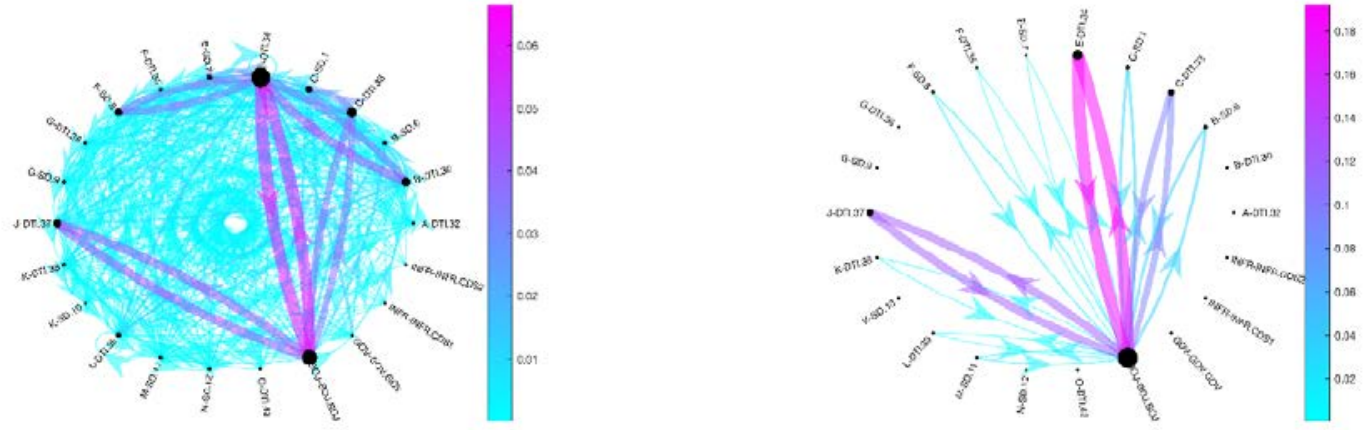

Sources: 2018 Jamaica FSAP (https://www.imf.org/ /media/files/publications/CR/2018/cr18347.ashx); Calculations based on Bank of Jamaica data. Note: DTI = deposit taking institution. Arrows display the direction of the payments (from sender to receiver), with the width and color of each arrow representing its contribution to total payments; the diameter of each node represents the contribution (i.e., importance) of the corresponding participant as sender of payments.

\section{Sovereign-Bank Linkages}

Balance sheet linkages between governments (sovereign) and banks are a classic and important amplification mechanism. In countries where linkages are high (e.g., some European countries as identified by the mapping exercise in Phase I), it would be useful to analyze this important link in detail. As in the interbank market, contagion channels work through actual exposures as well as market perceptions of risk dependence between banks and the sovereign. The sovereign-bank linkages could work through at least three channels (see Figure 24). First, bank claims on governments (e.g., holding of government bonds) represent the most direct link between these two sectors. Second, sovereign's contingent liabilities in the financial sector represent another channel of contagion when governments provide guarantees on certain liabilities of banks. Third, the bank funding channel could 
reflect market perception of risk dependence between the financial and the government sectors, including potential state support to the financial system. If bank equity indexes and sovereign bond yields co-move strongly, a lower sovereign rating could weaken bank profits through lower valuation effects and higher funding costs. Consequently, it could potentially affect investor confidence due to concerns related to a fiscal backstop.

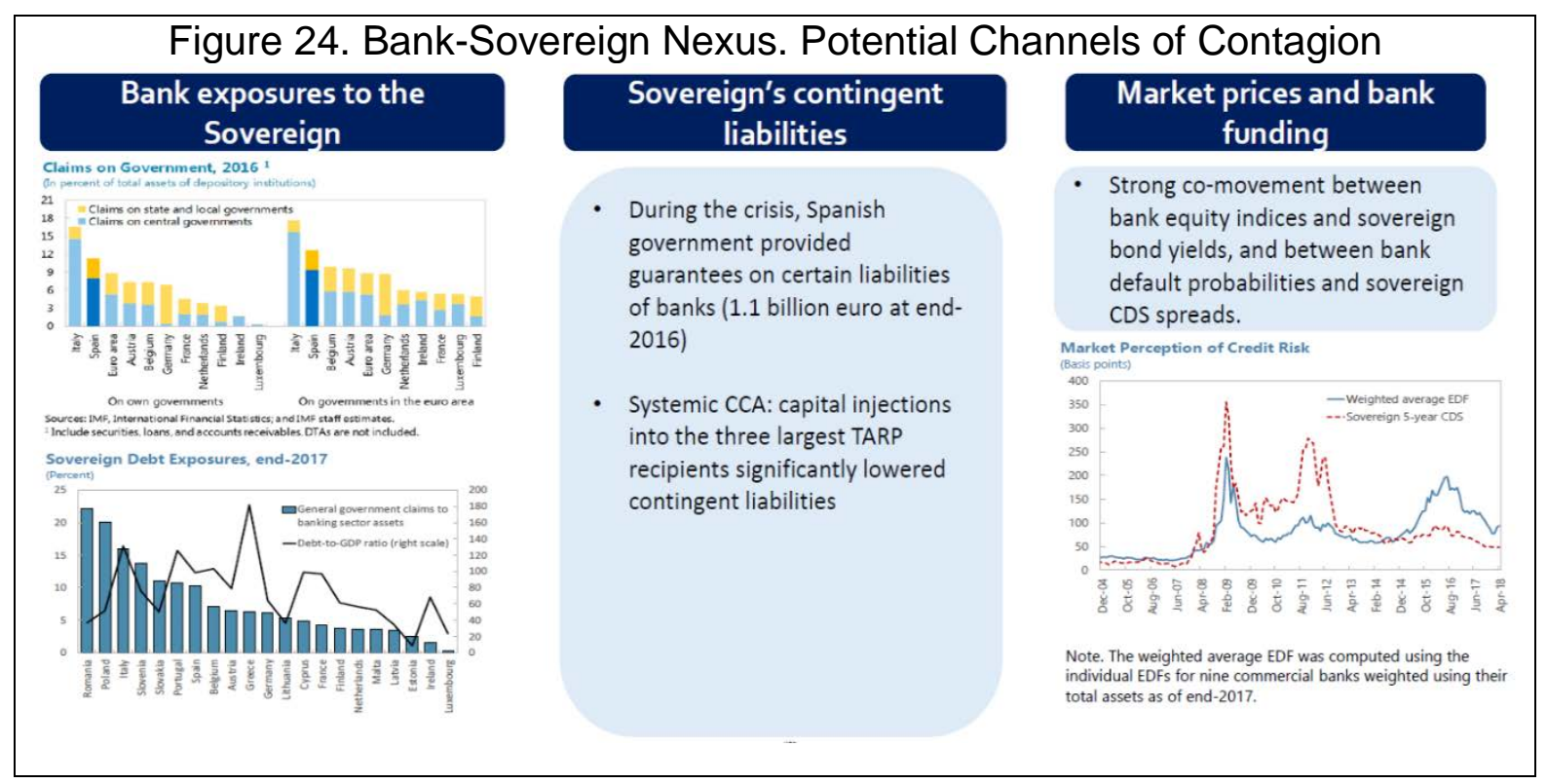

To analyze the first channel of bank exposures to sovereign (claims of banks on the government sector) one could either use data from the IMF's International Financial Statistics or from government authorities (if available).

Example: 2018 Romania FSAP. The FSAP team used exposure data from the National Bank of Romania and the European Banking Authority to analyze the intersectoral exposures between the Romanian sovereign and banking sectors (see Figure 25). The FSAP found that bank exposure toward sovereign risk was increasing, creating potential adverse banksovereign feedback loops. As of December 2017, the exposure of banks to the Romanian sovereign was about 22 percent of assets, increasing steadily from below 5 percent in 2008 to one of the highest in the EU. 


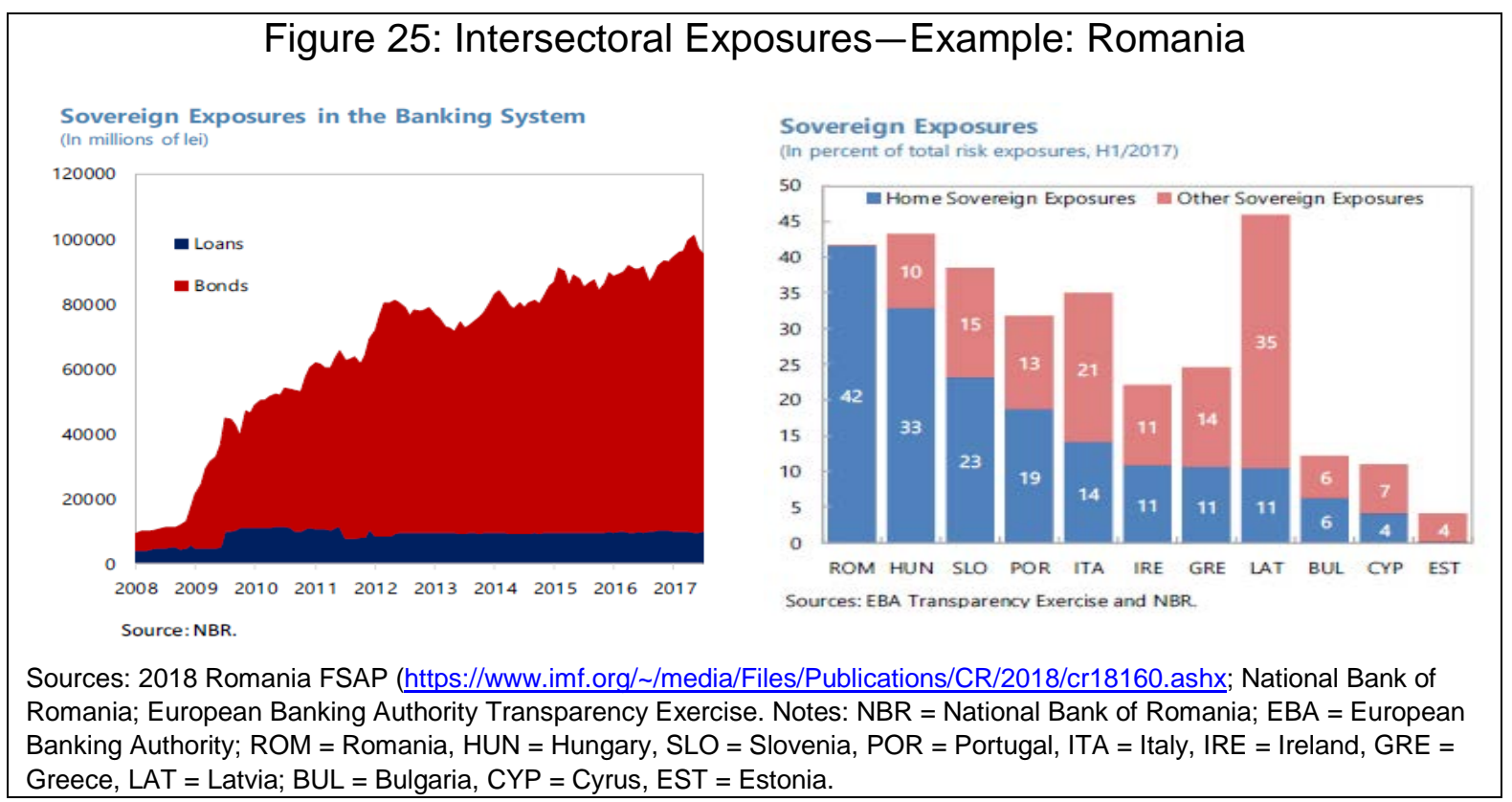

To analyze the second channel (a sovereign's contingent liabilities), one approach is the systemic contingent claim analysis by Gray and Jobst (2013). The systemic contingent claim analysis is an extension to firm-level contingent claim analysis (CCA). ${ }^{25}$ The systemic CCA identifies endogenous linkages affecting joint expected losses during times of stress, which can shed light on the joint tail risk of multiple entities. In systemic CCA, the magnitude of systemic risk posed by multiple institutions under distress is modeled as a portfolio of individual expected losses (with individual risk parameters) using equity market and balance sheet information. CCA and systemic CCA have been applied in several assessments under the FSAP, including the 2018 Euro Area FSAP and the 2010 U.S. FSAP.

Example: 2010 United States FSAP. This FSAP provides an example of a bank-sovereign nexus analysis (see Figure 26). ${ }^{26}$ The analysis shows that capital injections into the three largest recipients under the Troubled Asset Relief Program significantly lowered individual (market-implied) contingent liabilities and systemic tail risk.

\footnotetext{
${ }^{25}$ The CCA estimates the probability of default for one institution, and the systemic CCA estimates the joint probability of default of multiple institutions.

${ }^{26}$ In addition to other methods (CCA, SyRIN), the sovereign-bank nexus could be explored using the D-Y method, as was done using spreads in Alter and Beyer (2014).
} 
Figure 26: Market-Implied Contingent Liabilities of the Financial Sector-Example: United States

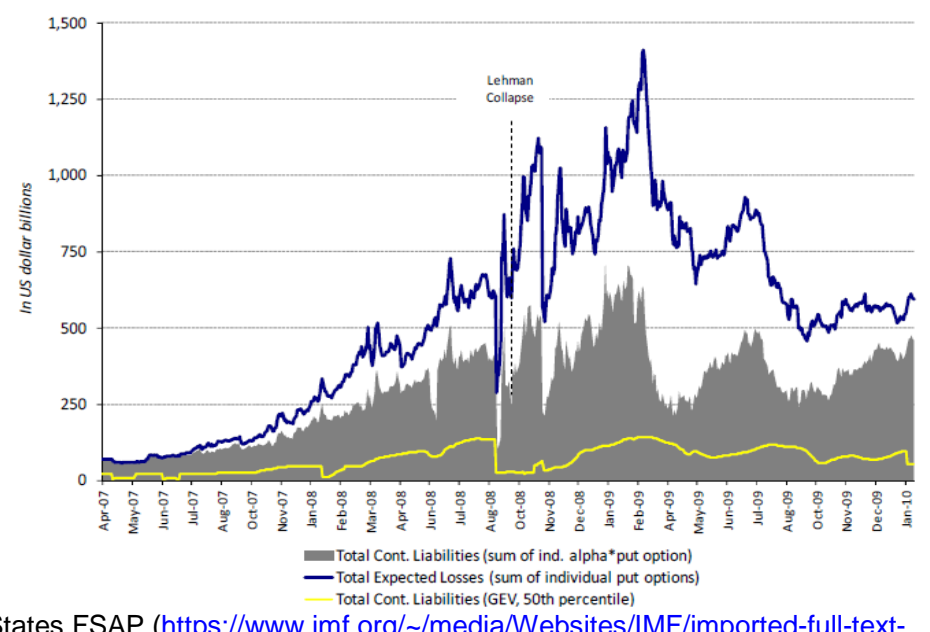

Source: 2010 United States FSAP (https://www.imf.org/ /media/Websites/IMF/imported-full-textpdf/external/pubs/ft/scr/2010/ cr10244.ashx).

To analyze the third channel (market prices and bank funding), it would be useful to analyze the extent to which bank equity indexes co-move with sovereign bond yields. Furthermore, it would be informative to analyze the extent of comovements between bank default probabilities (e.g., Moody's Expected Default Frequencies or CDS spreads) and sovereign credit default spreads, as these prices could help shed light on the market perception of credit risks (Figure 24, right).

\section{How to Analyze Cross-Border Interconnectedness and Contagion?}

The final part of Phase II is the analysis of cross-border linkages. A starting point of crossborder analysis could be a network analysis using direct exposure data, such as the EVS approach. To assess indirect cross-country linkages, one could apply the D-Y approach, based on (daily) equity returns or equity volatility data of banking indexes, to examine interconnectedness across countries. CoVaR is another market-based approach which uses equity data to estimate the value-at-risk of the financial system, conditional on institutions being under stress, with the Delta CoVaR capturing countries' contribution to systemic risks. If the focus of the analysis is more of a macro-financial nature, then the GVAR approach based on Dees and others (2007) could be a useful alternative, as it can be used to examine the cross-border impact of credit shocks, accounting for macro-financial interactions. The sample of countries in the cross-border analysis could be motivated by the mapping exercise (Phase I) based on the intensity of financial linkages.

As mentioned earlier, the EVS approach can be applied not only to financial institutions, but also to cross-border aggregate exposures, thereby providing insights on the resilience or vulnerability of a country's banking system. The EVS can capture the impact of both outward and inward spillovers and the subsequent impact on overall banking sector capital. In a cross-border context, the underlying input data for the network analysis could be 
aggregate banking sector claims (based on the BIS CBS or LBS), instead of the entity-toentity level data considered in the interbank or cross-sectoral analysis.

Example: 2017 Spain FSAP. EVS was used in this FSAP to assess cross-border interlinkages based on direct exposure data. Two sets of simulations were conducted using the BIS CBS. The first simulation applies to reporting banks' exposure to foreign banks only, considering both credit and funding shocks. The second considers the impact of credit shocks to the total exposure of the banking sector, including claims to banks, government, and the non-financial sector. For example, on inward spillover (Figure 27, top), France, the U.K., and the U.S. have the largest impact on Spanish banks when bank-to-bank exposures are considered. When all exposures are included, the U.K. and the U.S. remain important sources of credit shocks for Spanish banks. In addition, Spanish banks' exposures in Brazil, Mexico, Turkey, and Chile could also be significant for the transmission of credit shocks, due to the large claims on the nonbank private sector and the public sector in these countries. In terms of outward spillover (Figure 27, bottom), France and Italy appear to be influenced most by credit and funding shocks to their exposures in Spain, as measured by the percentage of capital loss in a banking system due to the default of all bank-to-bank exposures.

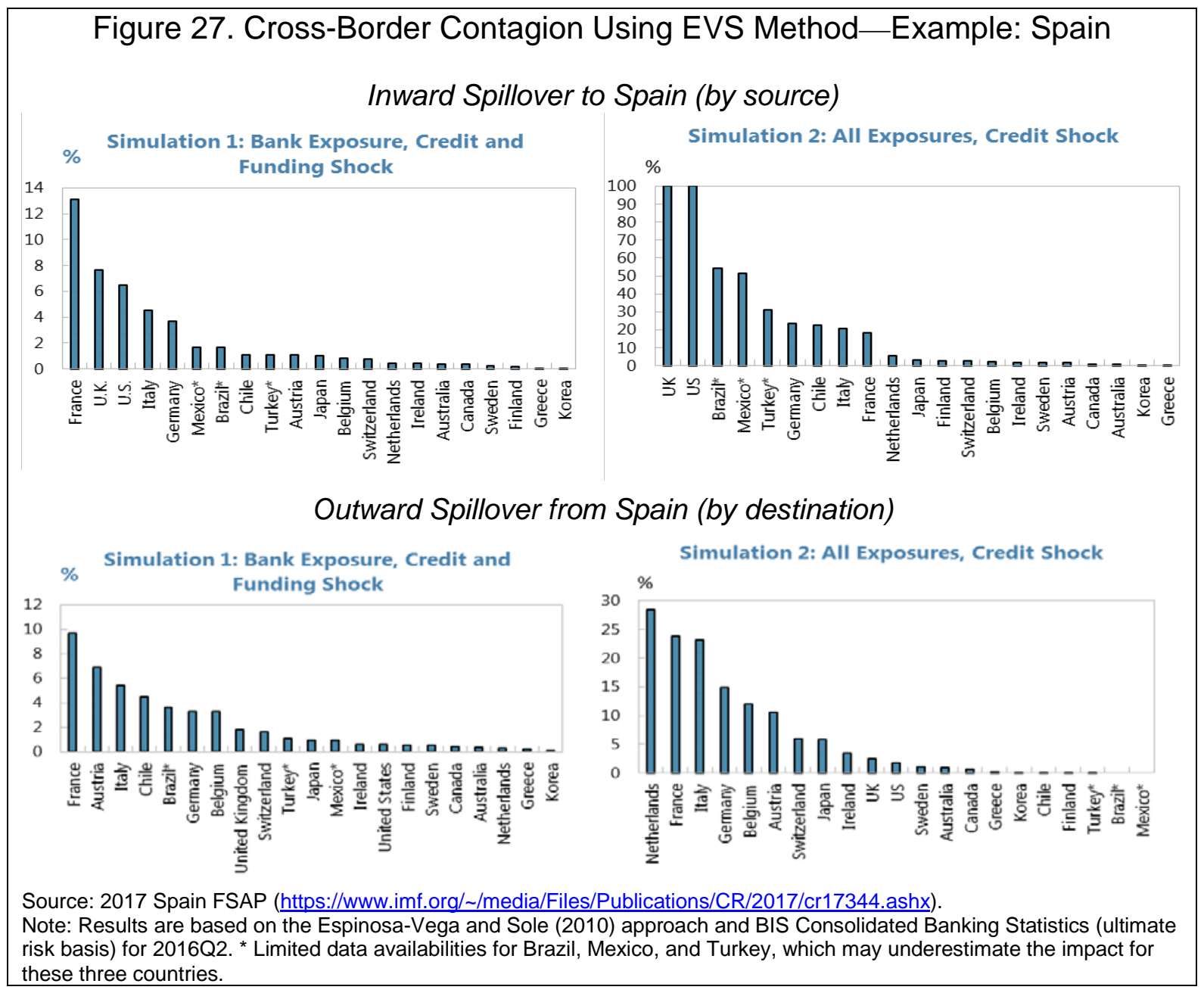


As for interbank analysis, the CoMap approach could be applied to cross-border analysis based on entity level data. For example, it was used in the 2018 Euro Area FSAP to analyze cross-border interconnectedness in the global banking network (Figure 15). Furthermore, the interbank syndicated loan data from Dealogic Loan Analytics could be used to construct a global banking network. ${ }^{27}$

In addition to the network analysis with exposure data, cross-border analysis is often complemented by market-based analysis using the D-Y approach, which captures marketbased indirect linkages and market perceptions. In cross-border analysis, the underlying data could be banking indexes for advanced and emerging market economies that have sizable exposures with the banking system of interest. In this case, the net directional connectedness measure is the difference between outward connectedness, that is the contribution of individual country's banking system to system-wide connectedness, and inward connectedness, which measures the impact of system-wide shocks on individual countries' banking systems. In addition to system-wide connectedness, it would also be useful to analyze the pair-wise connectedness between the banking system of interest and that in other countries, based on market data that captures investors’ perception of connectedness.

Example: 2017 Spain FSAP. In the case of Spain, indirect exposure was analyzed using DY methodology. The underlying data for this cross-border analysis were banking indexes for 16 advanced and emerging market economies that have large exposures with the Spanish banking system. Based on daily data from June 2005 to February 2017, market-based analysis suggests that European banks, especially from Germany, France, the U.K., and Spain, and U.S. banks are important net contributors to return connectedness in the global banking system (Figure 28, top). Pair-wise connectedness suggests that Spanish banks are highly connected with European banks (Figure 28, bottom), as shown by the network analysis. The banking indexes from France, the U.K., and Germany appear to be the source of return connectedness for Spanish banks. Furthermore, equity returns for the banking indexes in Mexico, Chile, Brazil, and Turkey are also influenced by Spanish banks.

27 See, for example, Hale (2012), Hale, Kapan, and Minoiu (2016), and Cai and others (2018). 
Figure 28. Interconnectedness among Banking Indexes_Example: Spain

Net Directional Connectedness: Equity Returns of Banking Indices
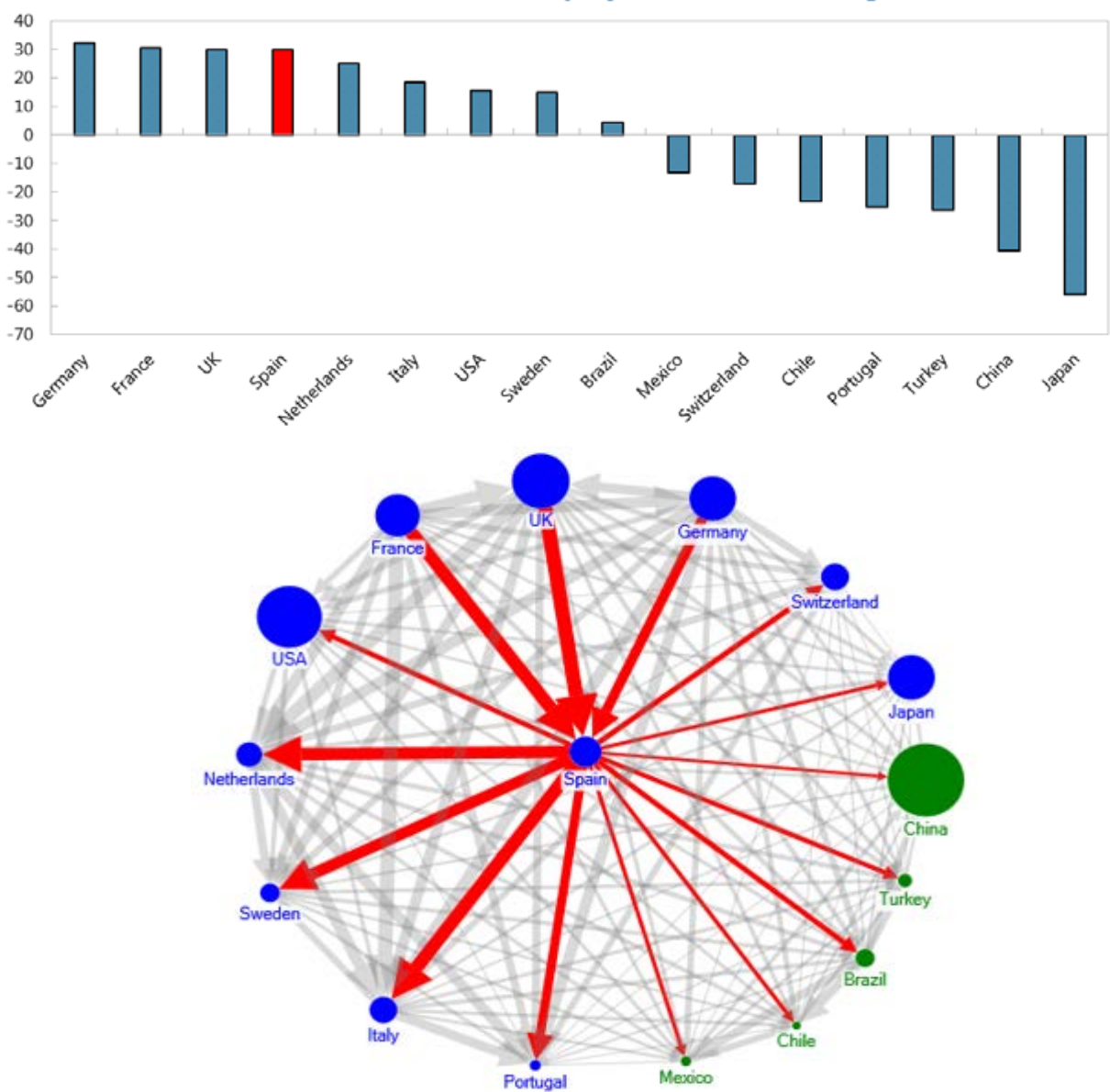

Note: Top panel: Using Spain as an example, net directional connectedness is constructed as the difference between the total directional connectedness to the system (the to-degree) and the total directional connectedness of the system (the from-degree). Bottom panel: The blue and green nodes denote developed countries and emerging market economies, respectively. The thickness of the edges reflects total connectedness (both inward and outward) and the direction of the arrow captures the direction of net connectedness. The size of the nodes reflects asset size. Chart constructed with NodeXL. Sources: 2017 Spain FSAP (https://www.imf.org/ /media/Files/Publications/CR/2017/cr17344.ashx); IMF Staff calculations based on the Diebold and Yilmaz (2014) methodology.

Another useful approach to analyze indirect contagion risk is the CoVaR, which can provide insights from a systemic risk perspective. Like the D-Y analysis, the input data for the CoVaR analysis could be banking indexes for economies with sizable exposures with the banking system of interest, or alternatively, the equity prices of the largest international banks of interest.

Example: 2017 New Zealand FSAP. To assess cross-border contagion, this FSAP considered a sample of global systemically important banks (GSIBs) and four Australian banks that are parent to New Zealand banks. The CoVAR analysis shows that the outward cross-border spillover from Australian banks to GSIBs are relatively contained (Figure 29, 
left). ${ }^{28}$ On the other hand, the inward cross-border spillover from distressed European GSIBs to New Zealand banks appears to be significant (Figure 29, right).

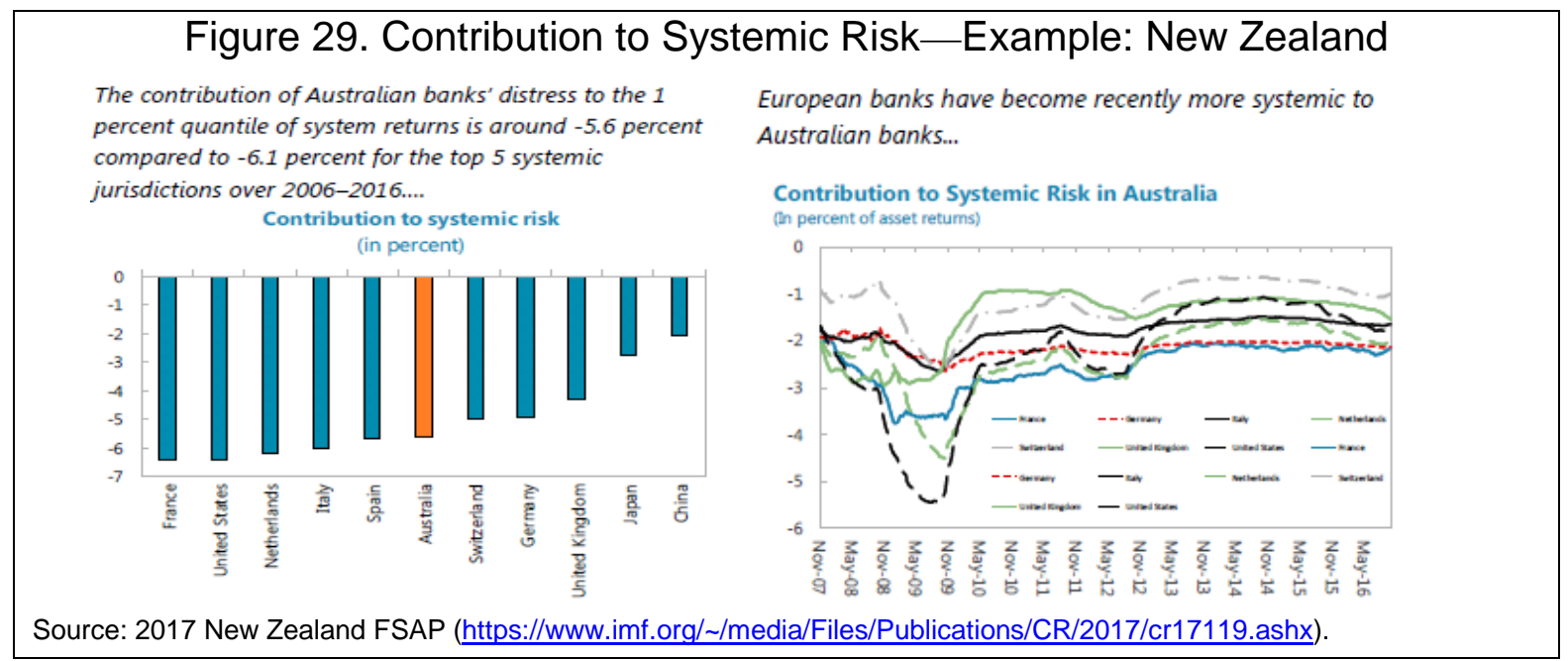

If the analysis of cross-border contagion is aimed toward a macro-financial perspective, then the GVAR approach can be used to examine cross-border spillovers. The GVAR methodology is a multi-country framework that captures macro-financial variables, including GDP, inflation, exchange rates, equity prices, credit, and interest rates. The GVAR model combines time series, panel data, and factor analysis techniques to address spillover issues. In the first step of the methodology, each country except the U.S. is modeled individually as a small open economy. Country-specific vector error-correction models are estimated, where domestic variables are related to country-specific foreign variables as well as global variables that are common across all countries (such as the international prices of oil). In the second step, a global model is constructed by combining all the estimated country-specific models and linking them with a matrix of cross-country linkages.

Example: 2017 Spain FSAP. In this FSAP, cross-country linkages are captured through both trade and banking exposures. The analysis examined the impact of a one-standard deviation shock to bank credit in Spain. The generalized impulse response functions (GIRFs) show that the transmission of Spain credit shocks to the United Kingdom and France takes place with a delay, with the impact on U.K. bank credit to be particularly strong (at about 0.5 percent) in eight quarters, possibly due to the strong linkages in the banking sector between Spain and the U.K. (Figure 30). This finding is consistent with the results based on exposure and market data, using the EVS and the D-Y approaches. Furthermore, the impact of credit shocks on Mexico appears to be limited, which could be attributed to the subsidiary model where local claims are largely funded by local liabilities.

\footnotetext{
${ }^{28}$ Since the New Zealand banks are subsidiaries of Australian banks, no equity data was available for estimating their CoVaR; for these New Zealand banks the FSAP used Australian banks equity data as a proxy to derive the CoVaR.
} 
Figure 30. Cross-Border Spillover of Spain Credit Shock-Example: Spain

GIRFs of a one standard deviation negative shock to Spain real credit

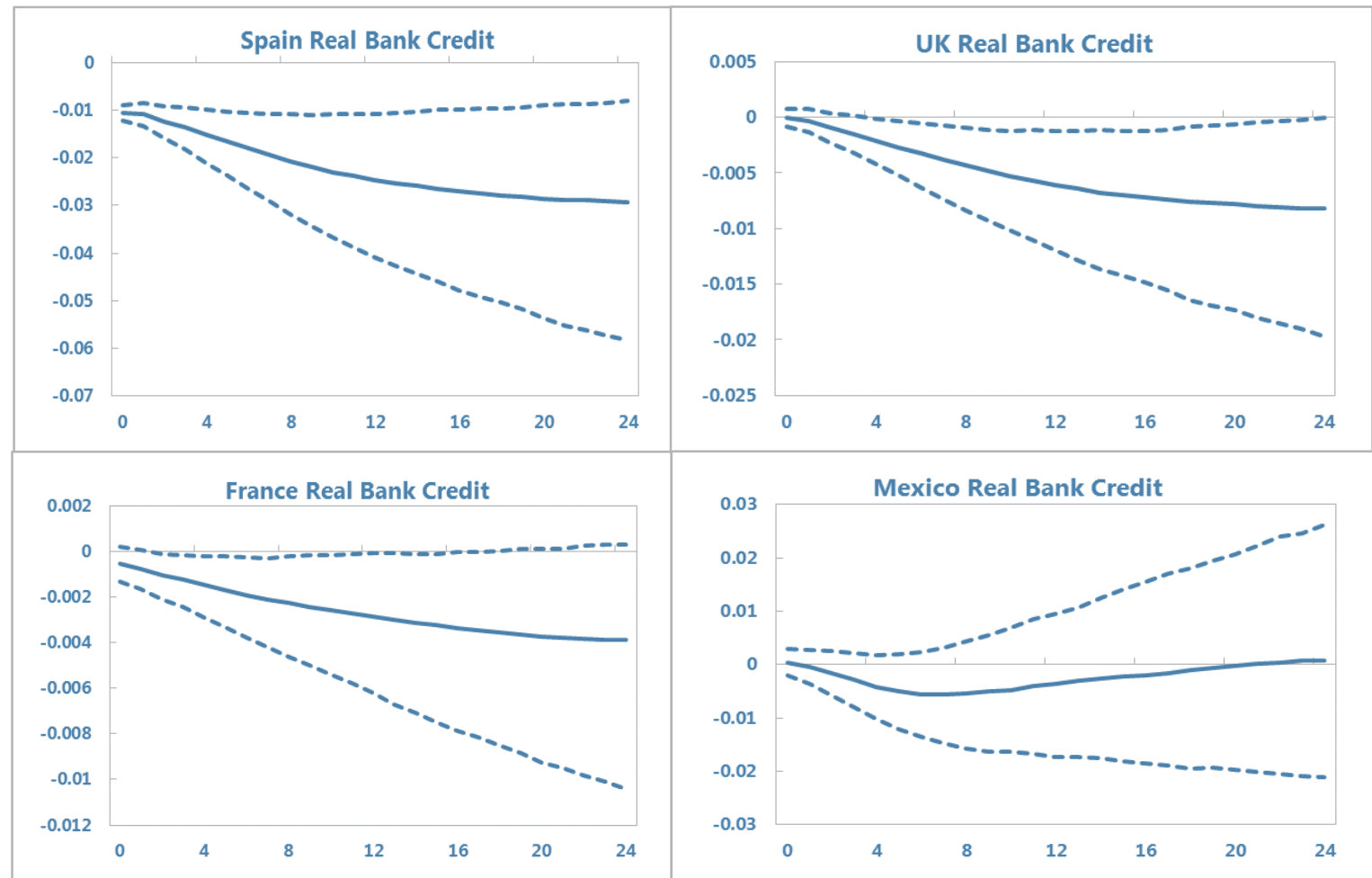

Source: 2017 Spain FSAP (https://www.imf.org/ /media/Files/Publications/CR/2017/cr17344.ashx).

Note: GIRF = generalized impulse response function. Estimated with a Global VAR model from 1979Q2 to 2016Q4 for 33

major advanced and emerging market economies. Each country specific model includes real GDP, inflation, the real

exchange rate, short-term and long-term interest rates, real equity prices, and real credit, where available.

\section{Practical Advice for the Presentation of Results and Policy RECOMMENDATIONS (PHASE III)}

The final phase of the interconnectedness and contagion analysis is the formulation of policy advice and recommendations. As mentioned earlier, a comprehensive interconnectedness and contagion analysis could rely on both exposure and market data. On the one hand, exposure data alone may not capture all indirect linkages and potential amplification channels. On the other hand, most market-data based models are not structural and typically cannot pinpoint the source of contagion. Furthermore, market prices might not always reflect financial sector fundamentals, especially when there is "irrational exuberance" or "fear" in investors' behaviors. Therefore, it would be advisable to apply both exposure- and market-based approaches and carry out several robustness checks, if data permits. In addition, conclusions and recommendations should not be based on individual results. Instead, the results of interconnectedness and contagion analysis should be viewed in conjunction with different work streams of financial stability analysis, including stress tests and non-bank and market analysis, to form a holistic view of risks and vulnerabilities in the financial system. The 
results from interconnectedness and contagion analysis could be used by policy makers to inform micro- and macroprudential policy advice (Figure 31).

Figure 31. Policy Discussion and Integration of Results (Phase III)

Phase III: Policy discussions - form view on Systemic Risks in the financial system
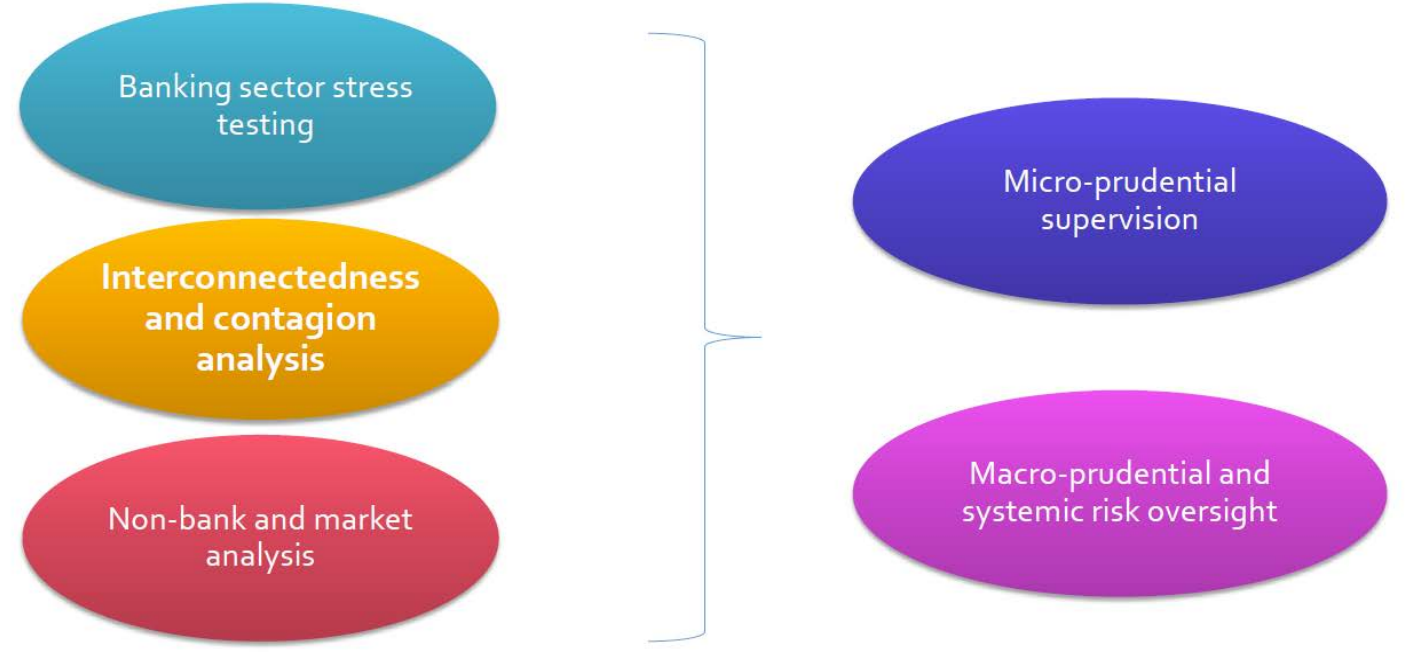

To understand the type of recommendations that can be derived from interconnectedness analysis, Table 2 provides some examples from past FSAP. Recommendations can be broadly grouped into four main areas: (i) monitoring and mitigating risks related to existing exposures, (ii) closure of data gaps, (iii) enhancement of contagion analytics, and (iv) improvement of cross-border supervisory coordination and resolution planning. The last group of recommendations also highlight how interconnectedness and contagion analysis could help inform the broader oversight of the financial sector regarding cross-border coordination on supervision and resolution.

The first group of recommendations is motivated by FSAP findings that there could be significant risks stemming from existing exposures that require close monitoring. A range of complementary tools can contain structural risks from interconnectedness and contagion within the financial system (Figure 32). Structural macroprudential policy tools target two objectives: (1) increasing the resilience of too-important-to-fail institutions; and (2) reducing excessive exposures within the financial system. To improve resilience and resolvability of those institutions whose failure poses systemic risks, prudential requirements can be tightened on those firms. To reduce the contagious effect from the failure of such institutions, prudential tools can be used to discourage exposures to these institutions or make such 
exposures more secure. ${ }^{29}$ In some cases, a reduction in the existing intra-group exposures would be warranted as they approach or breach limits.

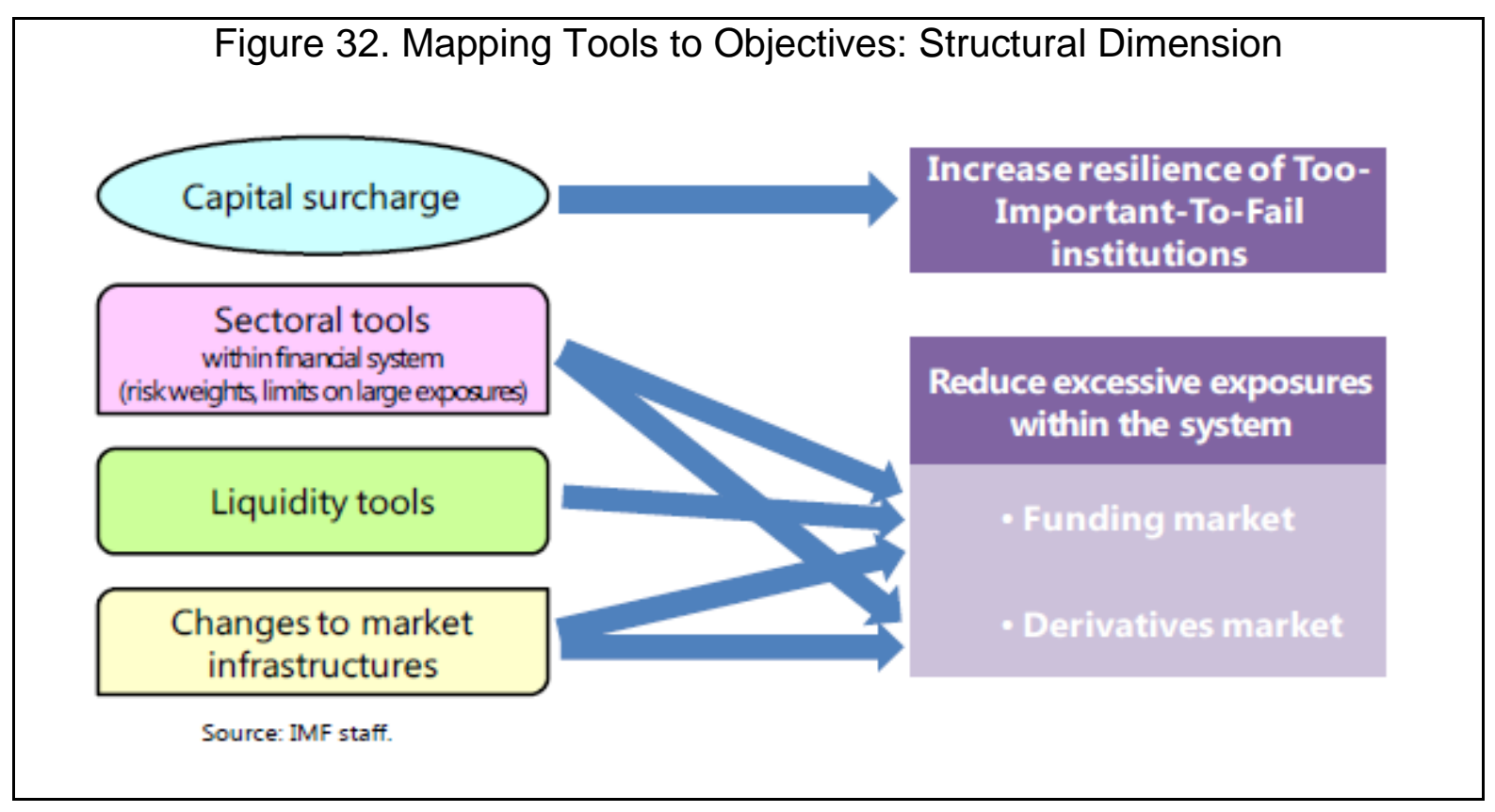

The second group of recommendations is driven by the identification of data gaps. The most common gap in data is related to cross-sectoral linkages at the entity level. This type of data is often not collected by national authorities, leaving these exposures unmonitored. In addition, there is often limited information on the evolution of these linkages over time. For a better understanding of the interconnectedness within a financial system and the potential feedback channels on the macro economy, it would be advisable to close the remaining data gaps on interconnectedness analysis. Furthermore, the G20 Data Gap initiative should also help close some of the remaining gaps on financial statistics (FSB and IMF 2018).

The third group of recommendations is related to an enhancement in the analytics of contagion analysis. In some countries, the interconnectedness analysis has largely focused on the interbank market, with limited coverage of cross-sectoral and cross-border dimensions. Unlike banking sector stress testing, the interconnectedness analysis is sometimes conducted on an ad-hoc basis, with little reference in the Financial Stability Report (FSR). In this case, FSAP teams have recommended an enhancement of the analytical tools for contagion analysis - to cover cross-sectoral and cross-border linkages, and to incorporate interconnectedness analysis in the FSR to help form an overarching view of systemic risks in the financial system.

\footnotetext{
${ }^{29}$ For more information on the application of structural tools to contain contagion, see IMF (2014) and Arregui and others (2013).
} 
Finally, the fourth group of recommendations concern cross-border supervision and resolution. In some countries, the interconnectedness analysis found strong linkages between subsidiaries and parent banks, where liquidity was "up-streamed" to the parent on a regular basis. While this is not necessarily an issue during normal times, it could be problematic in crisis times, especially for the resolution of failing institutions. In this case, the findings of interconnectedness analysis could have important implications for cross-border supervision and resolution. Past recommendations included a development of contingency resolution plans for foreign subsidiaries and an enhancement of inter-agency and college collaboration and coordination.

\begin{tabular}{|c|c|}
\hline & $\begin{array}{l}\text { Table 2. Past FSAP Recommendations Based on Interconnectedness and } \\
\text { Contagion Analysis }\end{array}$ \\
\hline \multicolumn{2}{|r|}{ Monitoring and mitigating risks related to existing exposures: } \\
\hline & 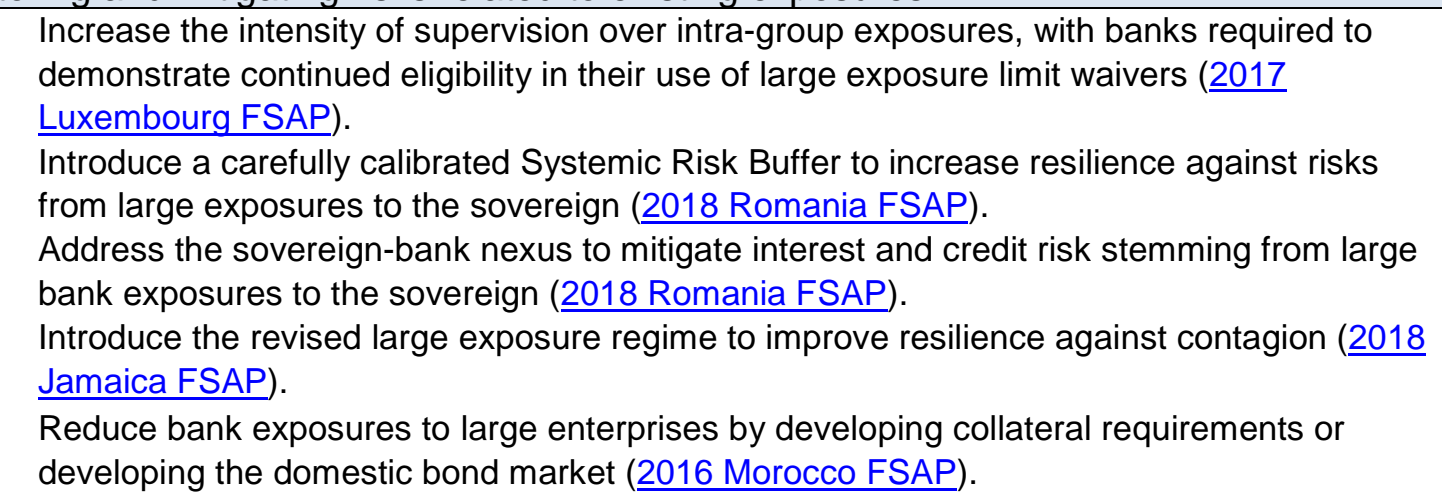 \\
\hline \multicolumn{2}{|r|}{ Closure of data gaps: } \\
\hline & $\begin{array}{l}\text { Close remaining data gaps on interconnectedness analysis with regards to interbank } \\
\text { exposures, cross holding of assets and liabilities by banks and non-banks, the derivative } \\
\text { exposure of banks and non-banks, the overall size and risk of non-traditional banking } \\
\text { activities within banks, and any perimeter supervisory issues (2017 Spain FSAP). } \\
\text { Close data gaps and improve data for credit risk and interconnectedness analysis ( } \underline{2019} \\
\text { Poland FSAP). } \\
\text { Improve the quality of metadata reporting on large exposures. Close data gaps on funding } \\
\text { sources by expanding the scope beyond the } 10 \text { largest counterparties (2017 Luxembourg } \\
\text { FSAP). } \\
\text { Enhance data collection and technical skills needed for risk-based supervision, including } \\
\text { frequency, granularity, and quality, with a focus on exposures data for analysis (2018 } \\
\text { Jamaica FSAP). } \\
\text { Address data gaps that impede systemic risk monitoring and effective financial regulation } \\
\text { and supervision ( } 2017 \text { China FSAP). }\end{array}$ \\
\hline \multicolumn{2}{|r|}{ Enhancement of contagion and stress testing analysis } \\
\hline & 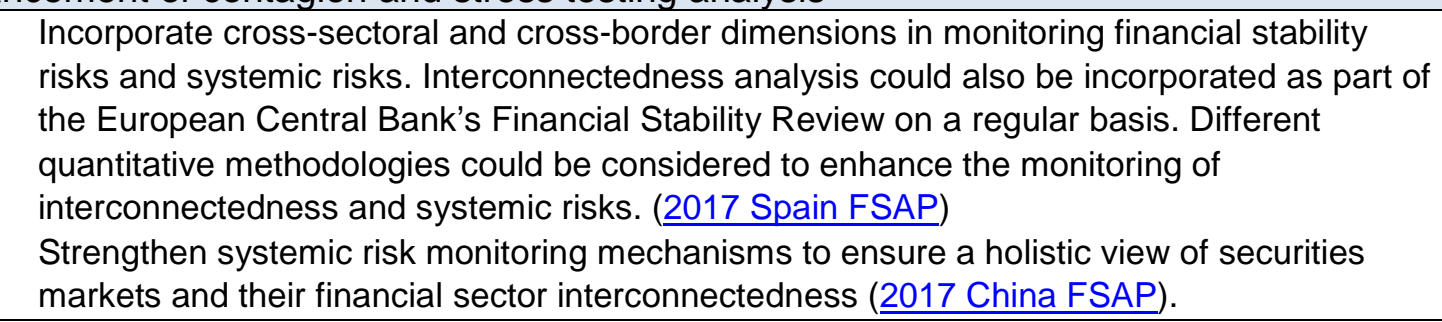 \\
\hline
\end{tabular}


- Continue to strengthen risk-based monitoring of the residential real estate market and bank-investment fund interlinkages, and close remaining related data gaps (2017 Luxembourg FSAP).

Improvement of cross-border supervisory coordination and resolution planning

- In the Nordic region, expand cooperation arrangements among regional supervisors to include (i) formal region-wide sharing of supervisory data and coordinated inspections, including foreign branches and cross-border management of investment funds, (ii) conduct Nordic stress tests, (iii) strengthen collaboration with macroprudential authorities, and (iv) enhance cooperation (under the Contingency Planning and Crisis Management framework) on systemically important branches and regular crisis simulation exercises (2016 Finland FSAP).

- Updated bilateral and multilateral cooperation MoUs (2016 Sweden FSAP).

- Provide more guidance for recovery and resolution planning (e.g., on defining critical functions, including with respect to custodian functions, and addressing large intragroup claims) (2017 Luxembourg FSAP).

- Improve inter-agency collaboration and coordination to form a more holistic view of systemic risks and to calibrate and enact macroprudential measures. Supervisors should strengthen their cross-border and cross-sectoral collaboration, given the potential channels of risk transmission (2017 Spain FSAP).

- Ensure that Romania's interests are addressed in recovery and resolution plans for Romanian subsidiaries of foreign banks (2018 Romania FSAP).

- Establish robust mechanisms for cooperation, coordination, and exchange of informationincluding granular financial data—with domestic and foreign safety-net participants ( $\underline{2017}$ China FSAP).

\section{CONCLUSION AND FUTURE Direction}

The analysis of interconnectedness and contagion forms an integral part of IMF's surveillance work and an important component of recent FSAP risk analysis. This paper provides an overview and examples of the commonly-used methods and techniques in FSAP (and other IMF products) to analyze financial interconnectedness and contagion from interbank, cross-sectoral, and cross-border dimensions. The interconnectedness analysis in these three areas is usually approached from two angles to capture direct and indirect linkages, using both exposure and market data. Before embarking on a meaningful interconnectedness and contagion analysis, it is advisable to map a country's financial system first, as shown in this paper through examples and suggestions.

While much progress has been made in interconnectedness and contagion analysis, more can be done to improve our understanding of the amplification channels in the financial sector and the broader economy. For example, more work is needed to improve our understanding of cross-sectoral contagion channels and financial-macroeconomic feedback loops. On crosssectoral analysis, data availability remains an important constraint to in-depth, entity-level analysis. More analysis is needed to better understand the linkages among banks, insurers, funds, and financial market infrastructures. One desirable approach is activity-based analysis that maps transactions in certain markets by all types of participants using data from clearing and depository institutions. Another area with data gaps is related to financial or non- 
financial conglomerates, including banks, non-bank financial institutions and non-financial firms. Complex group structures could potentially challenge the enforcement of related-party exposure limits and consolidated supervision, and complicate potential resolution processes. On financial-macro feedback loops, micro-level financial analysis (for example, stress tests and contagion analysis at the entity level) needs to be better integrated with macroeconomic dynamics. While some progress has been made to integrate stress test and contagion analysis, more needs to be done to integrate the macro-financial channels in stress testing and contagion analysis, and to link the contagion analysis with stress testing scenarios to analyze the baseline and adverse contagion behaviors.

Furthermore, new analytical tools such as machine learning, artificial intelligence, and "big data" could be applied to interconnectedness and contagion analysis. For network analysis, machine learning techniques and self-learning algorithms could be useful in exploring interconnectedness and contagion. For example, the Banco Central do Brazil has used big data from payment systems to build a real and financial sector network for contagion analysis. Machine learning techniques such as the clustering of unstructured data (e.g., newspaper reports on financial institutions) could also be used to identify contagion/market perception. For example, twitter messages were screened to derive an indicator of perceived interconnections and spillover effects for Italian banks (Accornero and Moscatelli 2018).

Finally, while progress has been made in using the results of interconnectedness and contagion analysis for policy making, as highlighted in our paper, more work needs to be done. Increasingly, microprudential policy has accounted for the importance of interconnectedness and contagion among financial institutions and across country borders. More progress would need to be made to incorporate financial contagion in macroprudential policy, especially regarding the calibration of macro-prudential tools. 


\section{REFERENCES}

Accornero, M., and M. Moscatelli. 2018. “Listening to the Buzz: Social Media Sentiment and Retail Depositors’ Trust.” Bank of Italy Working Paper 1165, Rome.

Acharya, V. V., R. Engle, and M. Richardson. 2012. “Capital Shortfall: A New Approach to Ranking and Regulating Systemic Risks.” American Economic Review 102 (3): 59-64. See also V-Lab: http://vlab.stern.nyu.edu/en/welcome/risk/.

Acharya, V. V., and A. V. Thakor. 2016. “The Dark Side of Liquidity Creation: Leverage and Systemic Risk.” Journal of Financial Intermediation 28 (C): 4-21.

Adrian, T., and M. Brunnermeier. 2016. “CoVaR.” American Economic Review 106 (7): 1705-1741.

Aghion, P., P. Bolton, and M. Dewatripont. 2000. “Contagious Bank Failures in a Free Banking System.” European Economic Review 44 (4-6): 713-718.

Aldasoro I., and T. Ehlers. 2019. "Concentration in Cross-border Banking.” BIS Quarterly Review, June, Bank for International Settlements, Basel, Switzerland.

Allen, F., and A. Babus. 2009. "Networks in Finance.” Wharton Financial Institutions Center Working Paper 08-07, 1-20, University of Pennsylvania, Philadelphia.

Allen, F., and D. Gale. 2000. "Financial Contagion." Journal of Political Economy 108 (1): $1-33$.

Alter A., and A. Beyer. 2014. “The Dynamics of Spillover Effects During the European Sovereign Debt Turmoil.” Journal of Banking and Finance 42 (May): 134-153.

Alter, A., B. R. Craig, and P. Raupach. 2015. “Centrality-Based Capital Allocations.” International Journal of Central Banking 11 (3): 329-377.

Arregui N., M. Norat, A. Pancorbo, and J. Scarlata. 2013. “Addressing Interconnectedness: Concepts and Prudential Tools.” IMF Working Paper 13/199, International Monetary Fund, Washington, DC.

Bank for International Settlements. 2015. “Introduction to BIS statistics.” BIS Quarterly Review, September, pp. 35-51.

Beirne J., and J. Gieck. 2014. “Interdependence and Contagion in Global Asset Markets.” Review of International Economics 22 (4): 639-659.

Benoit, S., J.-E. Colliard, C. Hurlin, and C. Pérignon. 2017. "Where the Risks Lie: A Survey on Systemic Risk.” Review of Finance 21 (1): 109-152. 
Bisias, D., M. Flood, A. Lo, and S. Valavanis. 2012. "A Survey of Systemic Risk Analytics.” Annual Review of Financial Economics 4 (1): 255-296.

Blancher, N. R., S. Mitra, H. Morsy, A. Otani, T. Severo, and L. Valderrama. 2013. “Systemic Risk Monitoring (“SysMo”) Toolkit-A User Guide.” IMF Working Paper 13/168, International Monetary Fund, Washington, DC.

Boss, M., H. Elsinger, M. Summer, and S, Thurner. 2004. "Network Topology of the Interbank Market.” Quantitative Finance 4 (6): 677-684.

Cai, J., F. Eidam, A. Saunders, and S. Steffen. 2018. "Syndication, Interconnectedness, and Systemic Risk.” Journal of Financial Stability 34 (C): 105-120.

Cerutti, E., S. Claessens, and P. McGuire. 2012. "Systemic Risks in Global Banking: What Available Data can tell us and What More Data are Needed?” NBER Working Papers 18531. National Bureau of Economic Research.

Cifuentes, R., and H. S. Shin, and G. Ferrucci. 2005. "Liquidity Risk and Contagion." Journal of the European Economic Association 3 (2-3): 556-566.

Čihák, M. 2007. "Introduction to Applied Stress Testing." IMF Working Paper 07/59, International Monetary Fund, Washington, DC.

Cingano, F., F. Manaresi, and E. Sette. 2016. “Does Credit Crunch Investment Down? New Evidence on the Real Effects of the Bank-Lending Channel.” Review of Financial Studies 29 (10): 2737-2773.

Cont, R., and E. Schaanning. 2017. "Fire Sales, Indirect Contagion and Systemic Stress Testing.” Norges Bank Working Paper Series 2/2017, Oslo.

(July): 85-102. 2019. “Monitoring Indirect Contagion.” Journal of Banking \& Finance 104

Cortes F., P. Lindner, S. Malik, and M. A. Segoviano. 2018. “A Comprehensive Multi-Sector Tool for Analysis of Systemic Risk and Interconnectedness (SyRIN).” IMF Working Paper 18/14, International Monetary Fund, Washington, DC.

Covi, G., M. Z. Gorpe, and C. Kok. 2019. "CoMap: Mapping Contagion in the Euro Area Banking Sector." IMF Working Paper 19/102, International Monetary Fund, Washington, DC.

Crosbie, P., and J. Bohn. 2003. “Modeling Default Risk.” Moody’s KMV Company.

Dees, S., F. di Mauro, M. H. Pesaran, and L. V. Smith. 2007. "Exploring the International Linkages of the Euro Area: A Global VAR Analysis.” Journal of Applied Econometrics 22 (1): 1-38. 
Diebold F. X., and K. Yilmaz. 2014. “On the Network Topology of Variance

Decompositions: Measuring the Connectedness of Financial Firms.” Journal of Econometrics 182 (1): 119-134.

Demirer, M., F. X. Diebold, L. Liu, and K. Yilmaz. 2018. "Estimating Global Bank Network Connectedness.” Journal of Applied Econometrics 33: 1- 15.

Eickmeier, S., and T. Ng. 2015. "How do U.S. Credit Supply Shocks Propagate Internationally? A GVAR Approach." European Economic Review 74 (C): 128-145.

Espinosa-Vega, M. A., and J. Sole. 2010. "Cross-Border Financial Surveillance; A Network Perspective." IMF Working Paper 10/105, International Monetary Fund, Washington, DC.

Fique, J. 2017. “The MacroFinancial Risk Assessment Framework (MFRAF), Version 2.0.” Technical Report 111, Bank of Canada, Ottawa.

Forbes, K. J. 2012. “The "Big C”: Identifying Contagion." NBER Working Paper 18465, National Bureau of Economic Research, Cambridge, MA.

Forbes, K. J., and R. Rigobon. 2002. “No Contagion, Only Interdependence: Measuring Stock Market Comovements.” Journal of Finance 57 (October): 2223-2261.

Freixas, X., B. M. Parigi, and J. Rochet. 2000. "Systemic Risk, Interbank Relations, and Liquidity Provision by the Central Bank." Journal of Money, Credit and Banking 32 (3): 611-38.

FSB and IMF (Financial Stability Board and International Monetary Fund). 2018. "Second Phase of the G20 Data Gaps Initiative (DG)-2: Third Progress Report.” IMF and the FSB Secretariat.

Gai, P., and A. Haldane, and S. Kapadia. 2011. "Complexity, concentration and contagion." Journal of Monetary Economics 58 (5): 453-470.

Gambacorta, L., and A. van Rixtel. 2013. "Structural Bank Regulation Initiatives: Approaches and Implications.” BIS Working Paper 412, Bank for International Settlements, Basel.

Glasserman, P., and H. P. Young. 2016. "Contagion in Financial Networks." Journal of Economic Literature 54 (3): 779-831.

Gray D., and A. A. Jobst. 2013. "Systemic Contingent Claims Anlysis - Estimating MarketImplied Systemic Risk.” IMF Working Paper 13/54, International Monetary Fund, Washington, DC.

Gupton, M., C. Finger, and M. Bhatia. 1997. “Credit Metrics Technical Document.” Morgan Guaranty Trust Company, Risk Management Research, New York. 
Hale, G. 2012. "Bank Relationships, Business Cycles, and Financial Crises.” Journal of International Economics 88 (2): 312-325.

Hale, G., T. Kapan, and C. Minoiu. 2016. "Crisis Transmission in the Global Banking Network." IMF Working Paper 16/91, International Monetary Fund, Washington, DC.

Hamilton, D. T., T. Hughes, and S. W. Malone. 2015. "Measuring Systemic Risk in Southeast Asian Financial System.” Moody’s Analytics. See https://www.economy.com/systemic-risk.

IMF (International Monetary Fund). 2014. "Staff Guidance Note on Macroeconomic Policy Detailed Guidance on Instruments.” International Monetary Fund, Washington, DC.

. 2015a. "Balance Sheet Analysis in Fund Surveillance.” Policy Paper, International Monetary Fund, Washington, DC.

. 2015b. “International Banking after the Crisis: Increasingly Local and Safer?” In Global Financial Stability Report -- Navigating Monetary Policy Challenges and Managing Risks. April. Washington, DC: International Monetary Fund.

. 2016. “The Growing Importance of Financial Spillovers from Emerging Market Economies.” In Global Financial Stability Report -- Potent Policies for a Successful Normalization. April. Washington, DC: International Monetary Fund.

IMF, BIS, and FSB (International Monetary Fund, Bank for International Settlements, and Financial Stability Board). 2009. "Guidance to Assess the Systemic Importance of Financial Institutions, Markets and Instruments: Initial Considerations.” International Monetary Fund, Washington, DC.

Inaoka, H., T. Ninomiya, K. Taniguchi, T. Shimizu, and H. Takayasu. 2004. "Fractal Network Derived from Banking Transaction -- An Analysis of Network Structures Formed by Financial Institutions." Bank of Japan Working Paper 04-E-4, Tokyo.

Iyer, R., and J. Peydro. 2011. "Interbank Contagion at Work: Evidence from a Natural Experiment.” Review of Financial Studies 24 (4): 1337-1377.

Jobst, A. A., and D. F. Gray. 2013. "Systemic Contingent Claims Analysis; Estimating Market-Implied Systemic Risk." IMF Working Papers 13/54, International Monetary Fund, Washington, DC.

Malik, S., and T. Xu. 2017. "Interconnectedness of Global Systemically-Important Banks and Insurers.” IMF Working Paper 17/210, International Monetary Fund, Washington, DC.

McCauley, R., P. McGuire, and G. von Peter. 2010. "The Architecture of Global Banking: From International to Multinational.” BIS Quarterly Review, March, pp 25-37. 
Minoiu, C., C. Kang, V. S. Subrahmanian, and A. Berea. 2015. "Does Financial Connectedness Predict Crises?” Quantitative Finance 15 (4): 607-624.

Minoiu, C., and J. Reyes. 2013. “A Network Analysis of Global Banking: 1978-2010.” Journal of Financial Stability 9 (2): 168-184.

Paddrik M., S. Rajan, and H. P. Young. 2016. “Contagion in the CDS Market.” OFR Working Paper 16-12, Office of Financial Research, Washington, DC.

Pesaran, M., and Y. Shin. 1998. "Generalized impulse response analysis in linear multivariate models.” Economics Letters 58 (1): 17-29.

Segoviano M., and C. Goodhart. 2009. "Banking Stability Measures." IMF Working Paper 09/4, International Monetary Fund, Washington, DC.

Shleifer, A., and R. W. Vishny. 1992. "Liquidation Values and Debt Capacity: A Market Equilibrium Approach.” Journal of Finance 47 (4): 1343-1366.

Upper, C. 2011. "Simulation Methods to Assess the Danger of Contagion in Interbank Markets.” Journal of Financial Stability 7 (2011): 111-125.

Xu, T. 2012. "The Role of Credit in International Business Cycles." Bank of Canada Staff Working Papers 12-36, Ottawa. 